\title{
FACTORS THAT INFLUENCE BYSTANDER BEHAVIOR IN THE CYBERBULLY CONTEXT
}

\author{
A Thesis by \\ Jessica Ezra Niblack \\ Bachelor of Arts, Wichita State University, 2010
}

\author{
Submitted to the Department of Sociology \\ and the faculty of the Graduate School of \\ Wichita State University \\ in partial fulfillment of \\ the requirements for the degree of \\ Master of Arts
}

May 2013 
Copyright 2013 by Jessica Ezra Niblack,

All Rights Reserved 


\section{FACTORS THAT INFLUENCE BYSTANDER ENGAGEMENT IN THE CYBERBULLY CONTEXT}

The following faculty members have examined the final copy of this thesis for form and content, and recommended that it be accepted in partial fulfillment of the requirement for the degree of Masters of Arts, with a major of Sociology.

Jodie Hertzog, Committee Chair

Twyla Hill, Committee Member

Deborah Gordon, Committee Member 


\begin{abstract}
With the movement of bullying behaviors from the traditional school yard context into a new realm enhanced by technology; cyberbullying is quickly becoming more invasive and detrimental to adolescents in the modern world, leading to suicides (Tremlow, 2008), depressive symptomology (Ybarra, Alexander, and Mitchell, 2005), and school avoidance issues (Ahlfors, 2010). A vast amount of existing studies focus solely on cyberbullying victimization or perpetration (Lenhart, Madden, Smith, Purcell, Zickuhr, and Rainie, 2011; Vandebosch and Cleemput, 2009). However, the current research available on bystander engagement, specifically on how bystanders engage when faced with incidents of cyberbullying, is much more limited. The study at hand specifically focuses on the type of engagement enacted by bystanders (pro-social, which involves helping the victim, or traditional, which is ignoring the cyberbullying) when witnessing cyberbullying on popular Social Networking Sites (SNSs). Using secondary data collected by the Pew Research Center's Internet and American Life Project from 2011 and using Latane and Darley's (1970) bystander engagement model, the current research explores factors (ex.: sex, age, previous victimization, parental monitoring techniques) that may influence different types of engagement outcomes from bystanders. Initial findings suggest that approximately $88 \%$ of youth between the ages of 12 and 17 have witnessed cyberbullying exchanges on-line. The results of this exploratory study find that about $62 \%$ of adolescents are acting pro-socially while $74 \%$ are acting traditionally. Findings from the research will provide insights regarding cyberbullying for future research as well as possible implications for educators, administrators, and health care professionals working to encourage pro-social bystander engagement among youth.
\end{abstract}


1. INTRODUCTION

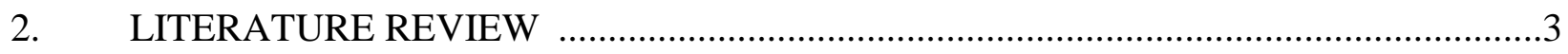

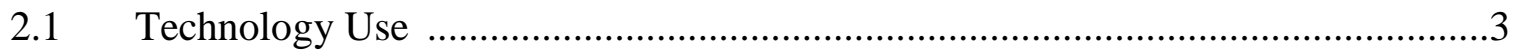

2.2 The Bully, Victim, Bystander, Triangle ................................................................6

2.2.1 The Bully .................................................................................

2.2.2 The Victim/Target............................................................................

2.2.3 The Bystander ...................................................................................... 10

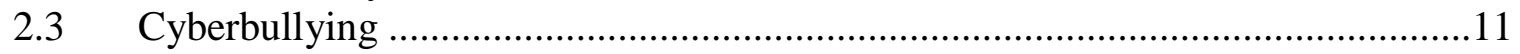

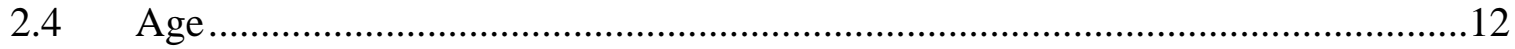

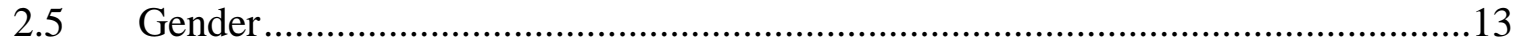

2.6 Parental Monitoring …………………………...........................................15

$2.7 \quad$ Bystander Engagement ………………………..............................................16

$2.8 \quad$ Research Questions/Hypotheses ………………............................................18

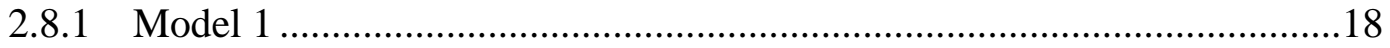

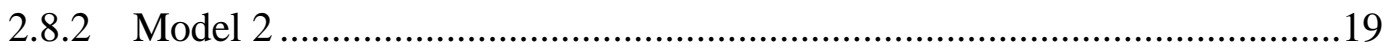

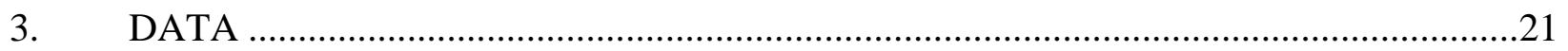

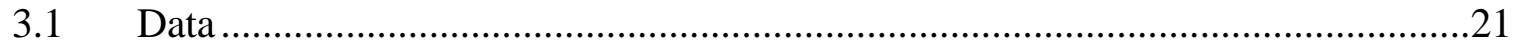

3.2 Dependent Variables ................................................................................22

3.2.1 Pro-social Bystander Engagement ........................................................22

3.2.2 Traditional Bystander Engagement.........................................................22

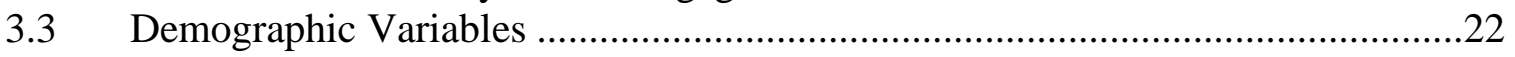

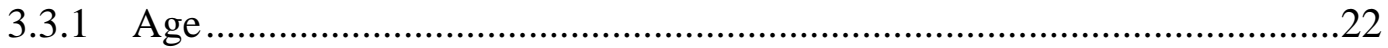

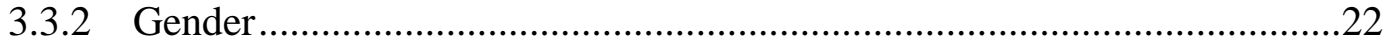

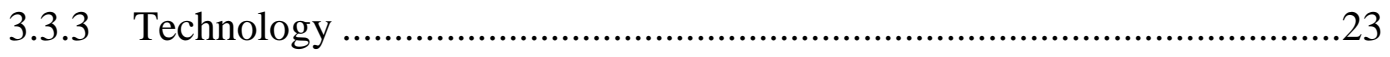

3.3.3.1 Frequency of Social Networking Site Use ………….....................23

3.3.3.2 Facebook, MySpace, Twitter User.................................................23

3.3.4 Parental Monitoring .....................................................................23

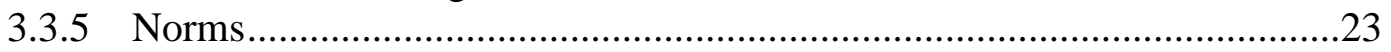

3.3.5.1 Perceptions of Cruel On-line Environment....................................23

3.3.5.2 Witness Pro-Social Engagement...................................................24

3.3.5.3 Witness Joining In...................................................................24

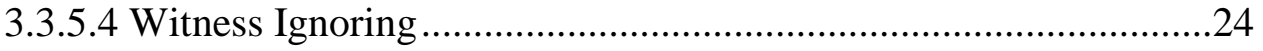


TABLE OF CONTENTS (continued)

Chapter

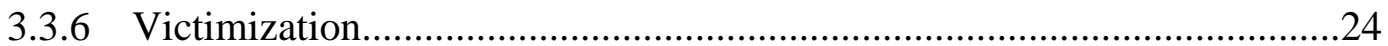

3.3.6.1 Social Networking Site Victimization in Last 12 Months ..............24

3.3.6.2 Overall Cyberbully Victimization Techniques ...............................25

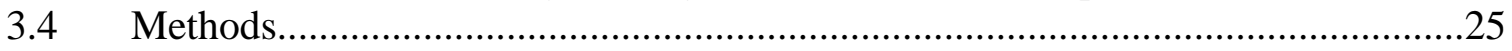

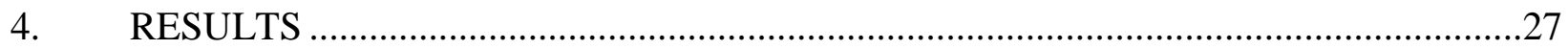

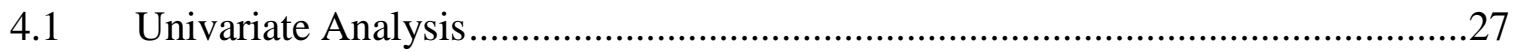

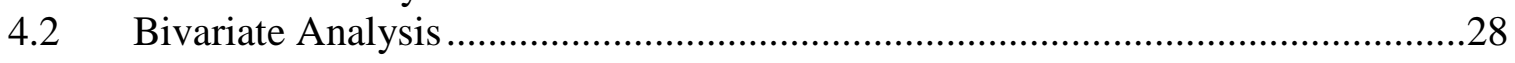

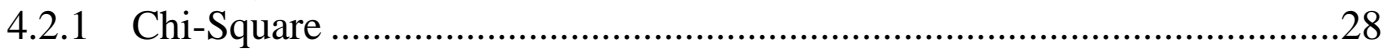

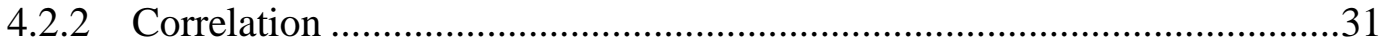

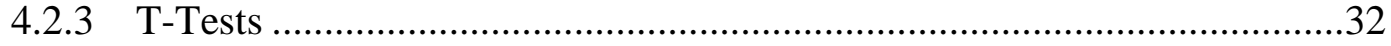

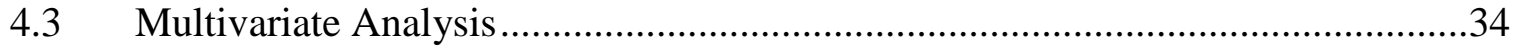

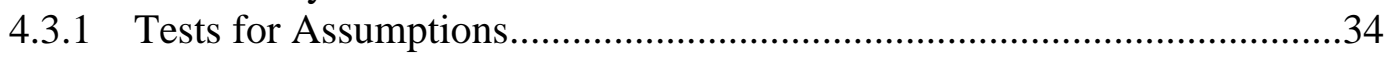

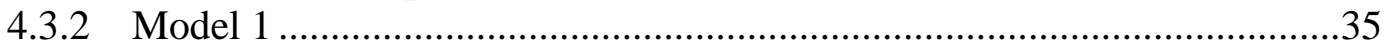

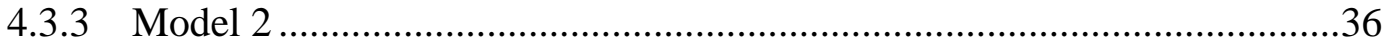

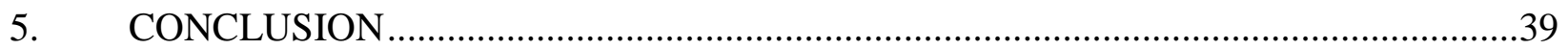

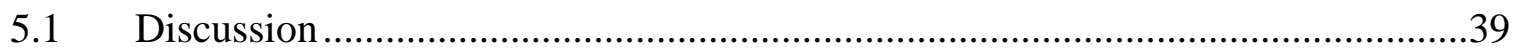

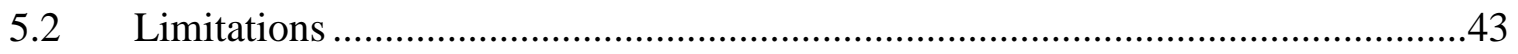

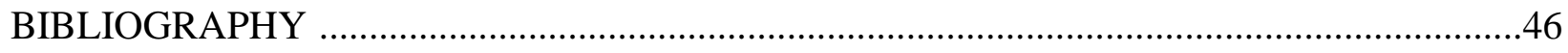

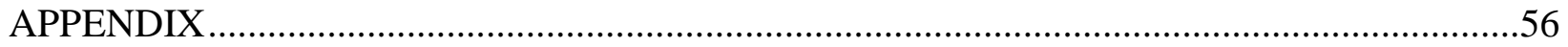

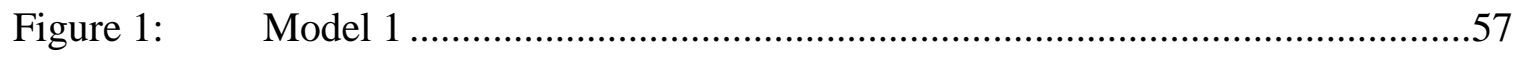

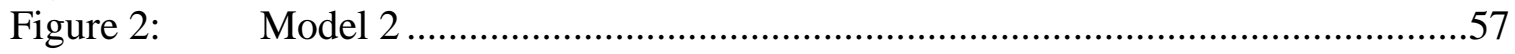




\section{LIST OF TABLES}

Table

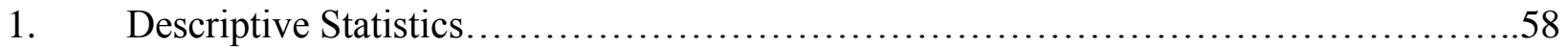

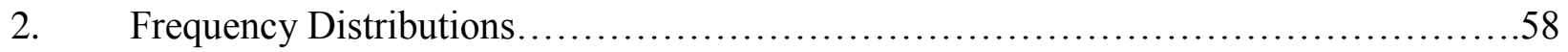

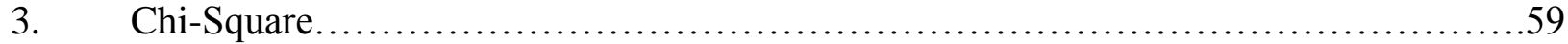

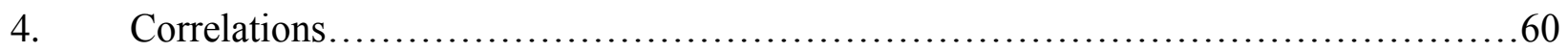

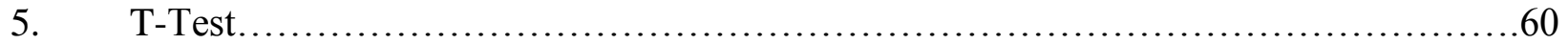

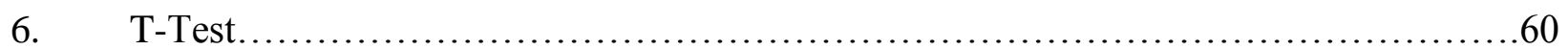

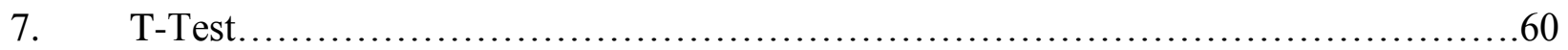

8. Model 1 Regression...........................................................61

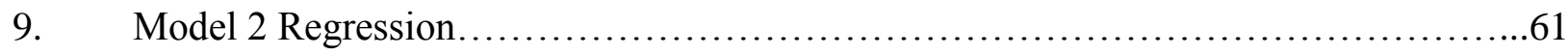




\section{CHAPTER 1}

\section{INTRODUCTION}

In the last twenty years electronic communication has evolved from receiving a page on one's beeper to electronic mail, Social Networking Sites (like Facebook, MySpace, and Twitter), instant messaging, chat rooms, and listserves, just to name a few. The options for communication in this modern era are seemingly endless and new tech options are being created at a rapid pace. Adolescents have latched onto these forms of communication; with $97 \%$ of adolescents 12-18 years of age reporting that they regularly use the internet (Kowalski and Limber, 2007). In addition, $90 \%$ of adolescents report they use technology mediated modes of communication to chat and instant message friends, post status updates on Social Networking Sites, and post comments to friend's statuses (Lenhart et. al., 2011). Finally, Mishna, Saini, and Solomon (2009) assert that electronic forms of communication are now viewed as "critical tools" in the social lives of the majority of adolescents.

While technological advancements bring many positive aspects, the popular media has become increasingly inundated with stories of potential risks youth may face in the cyber-sphere. At the forefront of these discussions are the ways in which technologies are being used to change the face of bullying. As Twyman, Saylor, Taylor, and Comeaux (2010), point out, "being anonymous allows for reduced social accountability which may encourage individuals to engage in inappropriate behavior online" (p. 195). In addition, Kowalski and Limber (2007) found that in comparison to traditional bullying where the bully is known, many victims of electronic bullying do not know the identity of their cyberbully. Furthermore, in the cyber world bullies can hide behind ambiguous screen names and even hijack others' accounts. 
While increasing scholarly attention has been devoted to exploring the ways in which traditional bullying behaviors have entered the cyber sphere, little remains known about the reactions of potential bystanders who witness bullying online. How does the potential anonymity of the cyber world affect responses of other members of social network communities when instances of electronic bullying occur? The goal of the current exploratory study is to increase current knowledge of on-line bystander behavior by exploring the frequency of different forms of cyber victimization, uncovering the norms of bystander responses witnessed on social network sites, and assessing factors that may predict different bystander outcomes among youth.

Bystander engagement is an important factor to understand when addressing the problem of cyberbullying. As suggested by Latane and Darley (1970), there are several types of bystanders; those who act in a pro-social manner by helping or defending the cybervictim, those who join in on the harassment and bully the victim, and those who simply ignore the victimization taking place. A recent example is the rape of an intoxicated 16 year old girl by two high school athletes in Steubenville, Ohio while a group of teens at the party shared pictures and video of the incident through text and social networking sites but did nothing to intervene (Dahl, 2013).

In the cyberworld there are many voyeurs, many who participate, and many who instigate in various ways. This research is aimed at determining what adolescents are doing as bystanders in Social Networking Sites. Are adolescents acting pro-socially, joining in, or ignoring? This research also hopes to gain an understanding of what influences or hinders bystander engagement, of any type. By completing this research it is hoped that better programs are made available to adolescents that give them the tools and the confidence to act in a pro-social manner when confronted with cyberbullying. 


\section{CHAPTER 2}

\section{LITERATURE REVIEW}

\section{$2.1 \quad$ Technology Use}

The exponential growth of electronic and computer based communication and information sharing during the last decade has drastically altered individuals' social interactions, learning strategies, and choice of entertainment in particular. There is a rapid rise of social networking on the Internet created by the growing access and use of electronic communication tools such as e-mail, websites, instant messaging, webcams, chat rooms, social networking sites, blogs, and text messages, Internet updating services that include specific Web sites devoted to updating (the most popular being Twitter) or social networking sites with updating features (such as Facebook). The common features of profiles include personal information such as one's name, location, school affiliation, occupation, and personal interests such as favorite movies or music. Other vital components of the profile are pictures, videos, and the comments one's peers leave on the page (Ahn, 2011; Mishna et. al., 2009; Mitchell, Wolak, and Finkelhor, 2007; Pujazon-Zazik and Park, 2010; Raskauskas and Stoltz, 2007).

Many youth believe that electronic communication is a key tool that they need to boost their social life (Mishna et. al., 2009). Ahn (2011) states that "technology is a structuring factor. Features of technology, not the technology itself, enable and constrain how one uses that tool" (p. 1436). With advances made in our technological world that have afforded adolescents the ability to communicate in various ways and in a matter of seconds, it is no mystery as to why technology has become an important mainstay in an overwhelmingly large population of people's lives. Adolescents at the turn of the twenty-first century are being raised in an Internet- 
enabled world where blogs and social networking sites are competing with face-to-face and telephone communication as the dominant means and methods through which personal interaction takes place (Hinduja and Patchin, 2008; Pujazon-Zazik and Park, 2010).

Cyber victims are being tormented in various ways by the electronic media devices that adolescents cherish so deeply. There are two major electronic devices that young bullies can employ to harass their victims from afar. First, using a personal computer, a bully can send harassing e-mails or instant messages, post obscene, insulting, and slanderous messages to online bulletin boards, or develop Web sites to promote and disseminate defamatory content. Second, harassing text messages can be sent to the victim via cell phones, which many youth today have access to (Patchin and Hinduja, 2006; Raskauskas and Stoltz, 2007). Today's young wired generation increasingly relies on the Internet and other forms of technology for entertainment, information, personal help and advice, and more importantly for social connection and interactions, and chat rooms allow for immediate, direct communications between participants (Mishna et. al., 2009; Pujazon-Zazik and Park, 2010).

With all the seemingly endless upgrades for devices, having the newest can be an important factor in maintaining a social status. According to Patchin and Hinduja (2006), "cell phones have gained widespread popularity and use among the younger age groups because they are perceived as a status symbol and allow for conversations with friends in different physical spaces" (p. 149). The variety of devices available to adolescents, specifically the camera phone, may be used to wreak havoc. They are small, which makes them easy to conceal so that one may use it in a malicious way. Technology has advanced our society in more ways than can be listed, but it has also altered the face of bullying. The nature of adolescent peer aggression has evolved due to the proliferation of information and communications technology; and due to their unique 
characteristics, online environments might be perceived by youngsters as a very liberating platform on which to express themselves which creates an environment where adolescents are susceptible to negative social interactions (Erdur-Baker, 2010; Hinduja and Patchin, 2010; Mesch, 2009).

Teenagers are among the most prolific users of social networking sites and are a unique population of social networking site users because they are among the first to have grown up entirely surrounded by communication technologies. Almost 50\% of the teenage population use cell phones; $97 \%$ use the Internet, with 51\%, or approximately 45 million adolescents, using it on a daily basis (Kowalski and Limber, 2007). Seventy-four percent of adolescents have access to the Internet from their homes and the average time per day adolescents spent online was 84.9 minutes (Lee and Chae, 2007). Nearly half of all adolescents have cell phones, allowing them instant access to text messaging and European and U.S. studies have shown that $84 \%$ to $88 \%$ of adolescents use IM for communication with existing friends (Ahn, 2011; Dempsey, Sulkowski, Nichols, and Storch, 2009; Valkenburg and Peter, 2009; Williams and Guerra, 2007; Ybarra et. al., 2005).

With various game sites, social sites, and learning cites available on the Internet that adolescents have access to; it is no wonder "children spend more time on the computer than they do watching television" (Mishna et. al., 2009, p. 1224). While some positive outcomes emerge from Internet use, such as connectedness, unfortunately there are downfalls to Internet use as well. Using instant messaging, going to chatrooms, and keeping online journals or blogs were related to being harassed online. Frequently sending text messages, instant messages, and emails to their friends, were also shown to increase risk of victimization (Mesch, 2009; Wolak, Mitchell, Finkelhor, 2007). Technology has influenced bullying in a negative way by allowing 
perpetrators to send their hurtful cyber-teases by way of multiple forms of technology, such as text messaging, instant messenger, and e-mail, or via Facebook, MySpace, or Twitter (Kowalski and Limber, 2007; Madlock and Westerman, 2011; Mesch, 2009; Vandebosch and Cleemput, 2009).

How often one uses the computer to navigate the various on-line worlds is a potentially important predictor when determining if one may be victimized by a cyberbully. Research has previously shown that offenders tend to use the Internet significantly more frequently and with more proficiency than individuals who have been victimized; however, the more time respondents spent on the Internet the more likely they experienced cyberbullying (Ahlfors, 2010; Hinduja and Patchin, 2008). Using the computer or Internet is a two sided coin. The more one uses technology the more skilled they become, but "if students are not allowed to use new technologies and participate in online communities like social networking sites, they will not be able to develop the necessary skills and technical literacy that will be vital in the future" (Ahn, 2011, p. 1447-48 and 1448), which will raise their chances of becoming a victim. Mesch (2009) states that "youth are using the Internet as a space of activity" (p. 388), and the activity they are participating in is socialization. One possibility of not using the Internet for socialization is that one may be the victim of bullying without even knowing it. Adolescents could be spreading rumors or pictures about a person who lacks the awareness that something is even going on.

\subsection{The Bully, Victim, Bystander Triangle}

Research on traditional bullying suggests that in many instances bullying is not just a dyadic process between a bully and a victim but is a triangle involving others who become witness to bullying behaviors either directly or indirectly (Barhight, Hubbard, and Hyde, 2013; 
Coloroso, 2011; Evers, Prochaska, Van Marter, Johnson, and Prochaska, 2007; Gini, Albiero, Benelli, and Altoe, 2008; Gini, Pozzoli, Borghi, and Franzoni, 2008; Lodge and Frydenberg, 2005; McNamee and Mercurio, 2008; Salmivalli, 2010; Salmivalli and Voeten, 2004). The three main players within the bullying triangle, then, consist of the bully, the victim/target, and the bystander.

\subsubsection{The Bully}

Bullying behavior often involves an imbalance of power between the bully, victim, and potentially the bystander based on physical strength, to popularity, to academics (Coloroso, 2011; Jerome and Segal, 2003; McNamee and Mercurio, 2008; Oh and Hazler, 2009; Pozzoli, Gini, and Vieno, 2012; Smith, Mahdavi, Carvalho, and Tippett, 2006). Bullying has historically affected children and teenagers in specific contexts: while at school, while traveling to or from school, or in public places such as playgrounds and bus stops or other venues such as malls, restaurants, or at neighborhood hangouts (Mesch, 2009; Patchin and Hinduja, 2006). Technology however, has allowed cyberbullying to have a pervasive presence in the life of a victim beyond these limited contexts. Whereas in a much simpler time, one could duck out on a bully, take a different route to school, or hide out in their bedroom all weekend, technology has changed the face of bullying. Patchin and Hinduja (2006) state that "because of the advent and continued growth of technological advances, the transmutation of bullying has moved from physical to the virtual. Physical separation of the bully and victim is no longer a limitation in the frequency, scope, and depth of harm experienced and doled out. As instances for bullying are no longer restricted to real-world settings, the problem has matured" (p. 155). 


\subsubsection{The Victim/Target}

With the way social networking sites are set up, it is easy for an adolescent to end up a victim or target of cyberbullying. With one post, one status update, or one tweet, an adolescent's reputation can be challenged and witnessed by numerous voyeurs in a matter of seconds. Studies find that cyber harrassemnt for over a third of victims "involves information being posted or sent to someone else about the adolescent" (Ybarra, Mitchell, Wolak, and Finkelhor, 2006). Furthermore, as many as " $60 \%$ of adolescents have been ignored while on-line, $50 \%$ have reported being disrespected, about $30 \%$ have been called names, $21 \%$ have been threatened, $20 \%$ were picked on" (Patchin and Hinduja, 2006, pg. 158), and "29.3\% have had rumors spread about them by others" (Hinduja and Patchin, 2010, pg. 214).

Through these technological means victims of cyberbullying can be attacked frequently because they are constantly in contact with the virtual world through their cell phones and since cyberbullying can occur any time of day or night (Mesch, 2009; Patchin and Hinduja, 2006; Pujazon-Zazik and Park, 2010). According to Li (2006), 62\% of adolescents have been victimized by a cyberbully at least once and about $38 \%$ were victimized more than three times. Additionally, digital storage archives, provide the potential for or episodes of cyberbullying to be forever available on-line so that at any given time someone can re-read, re-look at, or rewatch the negative information posted about a target and therefore a victim may re-live the victimization over and over again (Law, Shapka, Hymel, Olson, and Waterhouse, 2012).

The victims or targets of cyberbullying may share certain characteristics or risk factors for being bullied. According to Ahmed and Braithwaite (2004), some victims come from homes that have high levels of hostility or dominating discipline styles. Victims often stand out to 
bullies in some way and may be older, have questionable sexual orientation, exhibit mental or physical disabilities, have non-normative body types, have out of style clothing, and are either very good or very poor at academics or athletics, or some victims may simply be considered nerds (Coloroso, 2011; Jackson, Cassidy, and Brown, 2009; McNamee and Mercurio, 2008; Sinclair, Bauman, Poteat, Koenig, and Russell, 2012; Ybarra et. al., 2006).

Research suggests that youth are being bullied in ways that could negatively affect their physical, social, and/or emotional adjustment, classmate relationships, school adjustment, cognitive functioning, development, and well-being. For example, Schneider, O'Donnell, Stueve, Coulter (2012) found that “students who received mostly D's and F's were twice as likely to be cyber-only victims" (p. 173). School related problems have been found to arise when one has been a cyberbully victim. Some of these issues with and in school consist of being unhappy at school, poorer grades, higher rates of skipping class, detentions and suspension, bringing weapons to school, increased dropout rates, and overall school adjustment issues (Ahmed and Braithwaite, 2004; Dempsey, et. al., 2009; Hinduja and Patchin, 2008; Jackson, et. al., 2009; Lwin, Li, and Ang, 2012; Raskauskas and Stoltz, 2007; Schneider, et. al., 2012; Sinclair, et. al., 2012; Twyman, Saylor, Taylor, and Comeaux, 2010; Ybarra, et. al., 2007; Ybarra, et. al., 2006;). Additionally, socialization issues may arise for victims including of loneliness, adolescents distancing themselves from others, having fewer friends, lower popularity, poorer relationships with peers, and poor social skills overall (Ahmed and Braithwaite, 2004; Madlock and Westerman, 2011; Wolak, et. al., 2007; Ybarra, et. al., 2007; Ybarra, et. al., 2006;).

Research finds that victims experience emotional problems are numerous as well. Of adolescents who have experienced cyberbullying, many suffer from anxiety, embarrassment, 
humiliation, anger, aggression, sadness, lower self-esteem, and stress (Dempsey, et. al., 2009; Lwin, et. al., 2012; Madlock and Westerman, 2011; Patchin and Hinduja, 2006; Raskauskas and Stoltz, 2007; Tokunaga, 2010; Twyman, et. al., 2010; Wolak et. al., 2007). As daunting and as numerous as these negative effects of victimization are, the list unfortunately does not end here. Some adolescents have been victimized so frequently and horrifically that in one case a boy hanged himself due to endless cyberbullying via instant messaging (Twemlow, 2008), and unfortunately this case is not the only instance of what is being coined cyberbullicide (Hinduja and Patchin, 2010). With all the problems that are related to cyberbully victimization it is easy to see that cyberbullying is indeed a serious issue that must be addressed.

\subsubsection{The Bystander}

When assessing the bullying triangle it is found that bystanders tend to make up the vast majority of a school's population (McNamee and Mercurio, 2008). Studies have shown that bystanders are present about $85 \%$ of the time (Barhight et. al., 2013; Lodge and Frydenberg, 2005; McNamee and Mercurio, 2008). The bystander in the triangle of bullying plays many different roles. There are the reinforcers, the outsiders, and the defenders or upstanders. The reinforcer engages in behaviors that support the bully. So, basically, reinforcers side with the bully and may participate by laughing or encouraging the bully to continue the victimization (Oh and Hazler, 2009; Salmivalli and Voeten, 2004; Thornberg, Tenenbaum, Varjas, Meyers, Jungert, and Vanegas, 2012). An outsider is the second role a bystander can play in the bullying triangle. These bystanders tend to remain uninvolved by not taking sides or defending the victim (Oh and Hazler, 2009; Thornberg et. al., 2012). Outsiders are usually what are described as traditional bystanders. Stueve, Dash, O’Donnell, Tehranifar, Wilson-Simmons, Slaby, and Link (2006) defines a bystander as someone who is present when an event is taking place but does not 
get involved. The final role a bystander can play in the triangle is the defender. Defenders help the victim. By siding with the victim, comforting or encouraging the victim to take a stand, or by displaying conflict resolution by trying to diffuse the bullying situation (Oh and Hazler, 2009). Defending actions have been shown to develop when adolescents have a greater sense of empathy. The goal of the defender is to promote pro-social change (Cowie, 2000; Dunn, 2009; Espelage, Green, and Polanin, 2011; Salmivalli and Voeten, 2004; Thornberg et. al., 2012).

\subsection{Cyberbullying}

According to the Center for Disease Control and Prevention (Hertz and David-Ferdon, 2008), electronic aggression can be defined as "any type of harassment or bullying (teasing, telling lies, making fun of someone, making rude or mean comments, spreading rumors, or making threatening or aggressive comments) that occurs through e-mail, a chat room, instant messaging, a website (including blogs), or text messaging” (p. 3). Existing research suggests cyberbullies tend to use a combination of the above technical outlets to bully someone. Adolescents on the receiving end of the combined attacks are often labeled poly-victims (Madlock and Westerman, 2011; Mitchell, Finkelhor, Wolak, Ybarra, and Turner, 2011). Of the vast amount of adolescents who are communicating via on-line technologies, studies show that around 15\% of those have actually experienced cyberbullying (Lenhart, et. al., 2011; Schneider, et. al., 2012). Cyberbullying is becoming an invasive problem for many adolescents and simply participating in Social Networking Sites increases the risk of being cyberbullied (Mesch, 2009). There are several risk factors that may increase ones chance of becoming a victim of cyberbullying. Age, gender, and parental monitoring have been shown to be important factors. 


\subsection{Age}

The age of the adolescent plays a role in the chances of being a victim of cyberbullying. It has been shown that as youth get older they increase their on-line use, which is in line with why high school age adolescents are at a greater risk for being bullied (Kowalski and Limber, 2007; Mesch, 2009; Vanderbosch and Cleemput, 2009; Ybarra and Mitchell, 2004). A study by Hinduja and Patchin (2010) found that about $19 \%$ of internet users who had been cyberbullied were between the ages of 10 and 17.

According to previous research, age has some influence on modes of bystander engagement adolescents choose to utilize as well. As an adolescent gets older both sympathy for and liking of the victim decrease (Gini, Pozzoli, et. al., 2008). Adolescents have been shown to seek advice. Age has an effect on where the advice comes from. Adolescents that are age 12 and 13 were found to look towards friends while older adolescents more often looked to parents for advice on how to handle cyberbullying (Lenhart et. al., 2011). Studies have also found that as an adolescent gets older the decision to defend decreases with students in higher grades admitting they would prefer to not get involved either against the bully or for the victim (Salmivalli and Voeten, 2004).

Targets of cyberbullying are often picked on due to their age. Ahn (2011), states that "national studies define teenagers as between the ages of 12-17" (p. 1436). It is at this age many teens become susceptible to victimization with as many as " $28 \%$ stating they had been bullied in the last six months and of those adolescents about one-fifth stated that the victimization had occurred at least once or twice a week" (Hinduja and Patchin, 2010, pg. 207). Research finds 
that cyberbully victimization risk increases as an adolescent becomes older, with a stark increase following the transition to high school (Ahlfors, 2010; Vanderbosch and Cleemput, 2009).

\subsection{Gender}

Research finds that females tend to use more varieties of on-line options for communication compared to boys. Girls are members of on-line communities, use instant messaging, and e-mail at higher rates than boys and are more inclined to partake in role playing, such as lying about their age or presenting false physical appearances as well (Espinoza and Juvonen, 2011; Jackson, et. al., 2009; Lee and Chae, 2007; Pujazon-Zazik, and Park, 2010). As mentioned previously, the cyber world allows for certain anonymity to its users. Females embrace this anonymity and this is a reason why some female cyberbullies prefer this method (Li, 2006). On-line, girls have the ability to exercise their powers by spreading rumors, socially excluding others, slandering, and engaging in good old fashioned gossip (Jackson, et. al., 2009; Wang, Iannotti, and Nansel, 2009). Because girls tend to use their words as weapons instead of their fists ( $\mathrm{Li}, 2006)$, there is not a more conducive environment for these types of actions than on-line. Boys, on the other hand, tend to be more aggressive towards their male peers including friends, so it may be more difficult to distinguish cyberbullying from typical boy antics (WilsonSimmons, Dash Tehranifar, O'Donnell, and Stueve, 2006). While these types of goading seem acceptable among males in society; males acting in an aggressive manner towards females is not viewed as acceptable (Laner, Benin, and Ventrone, 2001).

Gendered characteristics can also relate to pro-social bystander engagement. Behaviors such as empathy and self-efficacy, which were higher for girls, were positively related to prosocial bystander engagement (Gini, Albiero, et. al., 2008; Lwin, Li, and Ang, 2012). Victim 
liking which has been suggested to influence bystander engagement was also found to be higher for girls. Finally, females show higher levels of protective intentions than males overall (Gini, Pozzoli, et. al., 2008; Lwin, et. al., 2012). While girls have been shown to bully both boys and girls (Ahmed, 2008), girls have also been shown to be more of a helper than boys. Males and females clearly do things differently and cyberbullying is no exception. It has been shown that males are more likely to be the aggressor or ignore the situation while females were more likely to defend the victim in a pro-social manner (Ahmed, 2008; Banyard, 2008; Choi and Cho, 2012; Erdur-Baker, 2010; Lenhart, et. al., 2011; Li, 2006; Obermann, 2011). Other research has shown that females are more likely to play the outsider or defender roles (Choi and Cho, 2012). Being female has also been related to more positive bystander outcomes such as showing support for the victim, defending behavior, initiating constructive conflict resolution, or initiating third-party interventions, all compared to males (Ahmed, 2008; Banyard, 2008; Cowie, 2000; Gini, Pozzoli, et. al., 2008; Lodge and Frydenberg, 2005; Obermann, 2011; Oh and Hazler, 2009; Pozzoli, et. al., 2012; Salmivalli and Voeten, 2004).

Finally, gender has also been shown to play a role in those who will be victimized. For boys, sexual orientation or the way boys carry themselves influences their chances of victimization. If boys do not fit the masculine idea of their peers they may become a cyberbully victim. Boys who have been shown to have atypical gender related behaviors were found to be at a much greater risk for peer assault than boys who conform (Li, 2006; Pujazon-Zazik and Park, 2010). 


\subsection{Parental Monitoring}

Cyberbullying is becoming a serious concern regarding adolescents well-being. It is important for parents to protect their children. Parents have an option for protection against cyberbullying which consists of several techniques parents can use to control or monitor their adolescent's on-line activities. These consist of parental monitoring techniques which are used to protect children and are generally made up of four elements: parental supervision in cyberspace, communicating with the adolescent, tracking what and where the adolescent is going on-line, and disclosure of what the adolescent is doing (Liau, Khoo, and Ang, 2008; Mesch, 2009). Specific measures consist of discussions about internet use, discussions of on-line content, computer placement, restriction of certain websites, creating rules together about internet use, checking what websites the adolescents have been on, and what types of information adolescents have about themselves on-line, as well as the less effective method of "looking over the shoulder" monitoring (Lenhart, et. al., 2011; Liau, et. al., 2008; Mesch, 2009). One problem that was discovered with parental monitoring is the fact that while schools and all those within urge students to give information about a cyberbullying event, many of the parents are instructing their adolescents to stay out of the problem unless the incident involves a family member (Wilson-Simmons, et. al., 2006).

The literature on the topic of parental monitoring shows some inconsistencies with cybervictims and to what lengths parents are actually going to with regards to monitoring their children. Even though a parent practices monitoring techniques to protect their child, if the monitoring is not frequent enough, chances of victimization will increase (Ybarra and Mitchell, 2004). Be it the parents or the teens end, there is a disconnect between what parents report. Approximately $34 \%$ to $54 \%$ of parents state they are in fact using parental monitoring 
techniques, however only $19 \%$ to $39 \%$ of adolescents agree that their parents practice monitoring (Lenhart, et. al., 2011). Intentions versus action may explain some of the discrepancies in what parents say they are doing and what adolescents know their parents are doing. Many adolescents feel that adults are out of touch with technology and the prevalence of cyberbullying. Parents may feel that technology is simply intimidating or frightening (Ahlfors, 2010; Mishna et. al., 2009). With technology and the internet children can entertain themselves endlessly via the various communication methods available. Parental monitoring is greatly influential on how adolescents engage one another on the internet, be it pro-socially or traditionally (Mesch, 2009).

\subsection{Bystander Engagement}

Based on existing bystander engagement models, several factors must be addressed before the bystander can decide how to act. To begin, the bystander must first realize something is happening. At this point the bystander needs to determine if what is happening is cause for concern. Next the bystander must decide if it is their personal responsibility or duty to act. The bystander then has to determine what type of intervention method is needed. Finally, the bystander needs to act (Banyard, Moynihan, and Crossman, 2009; Banyard, Plante, and Moynihan, 2004; Latane and Darley, 1970; Stueve, et. al., 2006).

Social factors that influence bystander engagement as well. Many adolescents may indeed want to help a victim in crisis, but they may be afraid. Bystanders, adolescents specifically, do not want to get involved for fear of bodily harm, humiliation in front of peers, or legal problems (Darley and Latane, 1968). A very important influential factor is the presence of others in a crisis situation. Numerous studies have found that the more people who are present in a crisis situation the less likely the victim will receive help and it boils down to the thinking that 
someone else will certainly do something (Banyard, et. al., 2004; Choi and Cho, 2012; Critelli and Keith, 2003; Darley and Latane, 1968; Hudson and Bruckman, 2004; Obermann, 2011; Stueve, et. al., 2006). This line of thinking also carries over into the virtual world, specifically in chatrooms. Markey (2000) found that victims did not receive help as quickly or at all when there were several people involved in the chat thread. Social cues are important and lacking in the cyber realm. Due to the fact that one cannot see the expressions of victims the bystanders may not realize that the victim is upset, which gives the bully the feeling of being uninhibited (Hudson and Bruckman, 2004). The bully feels free to victimize because victimizing someone may not feel personal to them.

Several effective measures can be taken to increase the likelihood of someone acting in a pro-social manner. Bystanders will feel a greater sense of urgency to practice pro-social engagement if they are asked to help by their name, the bystander feels obligated for whatever reasons, if they are empathetic, belong to a group that promotes intervention, are aware of the problem, and have commonalities with the victim (Banyard, 2008; Banyard et. al., 2004; Choi and Cho, 2012; Markey, 2000; Stueve et. al., 2006). To date, no research has explored bystander reactions in the cyber sphere. To understand how bystander engagement occurs in the cyber world in relation to cyberbullying Latane and Darley's model of bystander intervention can be used to determine and understand the process of the different types of bystander engagement that occur on-line. Latane and Darley's (1970) original model states that for engagement to occur steps must be processed by the bystander. The bystander needs to notice, determine if the incident is serious, determine if it is their business, conclude as to what to do, then act or not.

In the virtual world one must first be involved and to do this they must participate in online activity by having a Social Networking Site, instant message or e-mail account, or through 
the other various ways to communicate electronically, be it texting or tweeting. This gives the users the opportunity to notice if an event of cyberbullying is taking place. The bystander then needs to determine if cyberbully victimization is occurring, consider whether they should become involved, determine which way they should get involved if they decide they will, and finally, act. For those bystanders who ignore the victimization, the chain of action would stop after they considered not getting involved. For those bystanders who determine to act, they can either engage as a bully themselves or they can engage in pro-social bystander engagement.

\subsection{Research Questions/Hypotheses}

The goal of the current research is to assess the following research questions:

1. How common is cyberbullying on social networking sites frequented by youth?

2. How do youth react to cyberbullying instances on popular social networking sites?

3. What factors influence traditional bystanding versus pro-social bystander engagement?

4. Do bystander outcomes vary across different types of SNS (ie, Facebook, MySpace, Twitter)?

Based on these research questions several hypotheses were created for two different models, pro-social bystander engagement and traditional bystander engagement, to determine what factors influence each mode of bystander engagement. The hypotheses for each model, beginning with model 1, pro-social bystander engagement, are as follows:

\subsubsection{Model 1: Pro-social Engagement (Appendix 1, Figure 1)}

1. The younger the adolescent the more likely they are to practice pro-social bystander engagement. 
2. Females are more likely to practice pro-social bystander engagement.

3. Adolescents who spend more time on-line are more likely to practice pro-social engagement.

4. Out of the three popular social networking sites, adolescents who use Facebook are more likely to practice pro-social bystander engagement.

5. The greater the parental monitoring techniques the less likely an adolescent will practice pro-social bystander engagement.

6. Adolescents who perceive cruel on-line behavior as normal are less likely to practice prosocial engagement.

7. Adolescents who witness others practicing pro-social behavior are more likely to do so as well.

8. Adolescent who witness others joining in or witness ignoring cyberbullying are less likely to engage in pro-social behaviors.

9. Adolescents who have been victimized in the last 12 months on a social networking site are more likely to practice pro-social engagement.

10. Adolescents who have experienced more overall cyberbully victimization techniques are more likely to practice pro-social engagement.

\subsubsection{Model 2: Traditional Bystander Engagement (Appendix 1, Figure 2)}

1. The older the adolescent the more likely they are to ignore victimization.

2. Males are more likely to ignore victimization.

3. Adolescents who spend more time on-line are less likely to ignore victimization.

4. Out of the three popular social networking sites, adolescents who use MySpace or Twitter are more likely to ignore cyberbullying. 
5. The greater the parental monitoring techniques the more likely an adolescent will ignore victimization.

6. Adolescents who perceive cruel on-line behavior as normal are more likely to ignore victimization.

7. Adolescents who witness pro-social engagement are less likely to ignore victimization.

8. Adolescent who witness others joining in or witness ignoring cyberbullying are more likely to ignore cyberbullying.

9. Adolescents who have been victimized in the last 12 months are less likely to ignore victimization.

10. Adolescents who have experienced more overall cyberbully victimization techniques are less likely to ignore victimization. 


\section{CHAPTER 3}

\section{DATA}

\subsection{Data}

The data used for this study was supplied by Pew Research Center's Internet and American Life Project and funded by the Pew Charitable Trusts (Princeton, 2011). Adolescents were eligible to participate in this random digit dial survey selected from telephone exchanges if they were a resident of the United States between the ages of 12-17, had parental consent to participate and lived in a household with a landline. The sample design uses a random generation of the last two digits of phone numbers chosen on the basis of their area code, telephone exchange, and bank number. The sample for the Internet and American Life Project was conducted between the dates of April $19^{\text {th }}$ to July $1^{\text {st }} 2011$ and consisted of 800 parent-teen pairs, with an oversampling of African-American and Latino families. A weight for the data was created based on the most recent data from the Census Bureau's 2011 American Community Survey. The sample is weighted from the Census Bureau's population parameters that consist of gender by age, gender by education, age by education, region race and Hispanic origin. These parameters are then compared with the sample characteristics to construct sample weights. The final weight is created to balance all weighting parameters (Princeton, 2011). For my analysis I chose the standard weight that was supplied so that the findings could be generalized to the population. 


\subsection{Dependent Variables}

\subsubsection{Pro-Social Bystander Engagement}

The first dependent variable that will be used in this study consists of whether the bystander engages in pro-social bystander engagement. Pro-social bystander engagement is defined as an adolescent defending the victim. Defending the victim is defined as whether the adolescent has ever stood up for the victim or acted on the victims behalf to stop the cyberbullying. The variables were first recoded so that zero represents never and three represents frequently. An index was created by combining the two. The variables were then relabeled so that zero represents never and six represents frequently engaged in both modes of pro-social bystander engagement.

\subsubsection{Traditional Bystander Engagement}

The second dependent variable used to determine what type of bystander engagement is occurring is if the adolescents are ignoring the cyberbullying incident. The variable was recoded so that zero represents never and three represents frequently.

\subsection{Demographic Variables}

\subsubsection{Age}

Age was a chronological variable ranging from 12-17.

\subsubsection{Gender}

Gender was recoded so that zero represents males and one represents females. 


\subsubsection{Technology}

\subsubsection{Frequency of Social Networking Site Us:}

Technology use assesses the frequency in which adolescents are logging onto social networking sites. This variable was recoded so one represents less often while six represents several times a day.

\subsubsection{Facebook, MySpace, Twitter User}

Three dichotomous variables were created to assess which social networking sites adolescents are using. Facebook, MySpace, and Twitter were the top three social networking sites listed with adolescents using Facebook the most. All three of these variables were recoded so that zero represent they do not use and one represents they use that social networking site.

\subsubsection{Parental Monitoring}

The amount of parental monitoring techniques adolescents believe their parents are using was assessed by creating an index of four different items: whether the parent used parental controls, checked or visited websites, checked social networking sites profiles, and/or used cell phone restrictions. The four techniques were combined and recoded in such a way that zero represents no parental monitoring techniques are used and four represents all techniques used.

\subsubsection{Norms}

\subsubsection{Perceptions of Cruel On-line Environment}

Norms are important in determining what adolescents consider acceptable or unacceptable behavior on social networking sites. Perceptions of cruel on-line behavior consists of how often an adolescent witnesses what they believe to be cruel behavior. This variable was 
recoded so that zero represents adolescents never see other adolescents acting cruel, and three represents adolescents witnessing cruel behavior frequently.

\subsubsection{Witnessing Pro-Social Behavior}

To determine how often adolescents witness others acting in a pro-social manner two measures were used. An adolescent may witness others practice pro-social bystander engagement which consists of telling the bully to stop or defending the victim. Each pro-social variable was first recoded so that zero represents never and three represents frequently with regards to adolescents witnessing someone defend the victim or tell the bully to stop. An index was then created combining these two variables. Variables were then relabeled so that zero represents never and six represents frequently witness both pro-social engagement modes.

\subsubsection{Witness Joining In}

The variable used to measure how often adolescent's witness others join in with the cyberbullying was recoded so that zero represents never and three represents frequently.

\subsubsection{Witness Ignoring}

The variable used to measure how often an adolescent witnesses others ignoring the cyberbullying was recoded so that zero represents never and three represents frequently.

\subsubsection{Victimization}

\subsubsection{Social Networking Site Victim in Past 12 Months}

Two variables were used to measure an adolescent's prior victimization. The first variable determined victimization on social networking sites in the last twelve months. 
Respondents were asked if they had been victimized on a social networking site in the last twelve months. The variable was recoded so that zero represents no and one represents yes.

\subsubsection{Overall Cyber Victimization Techniques}

The second measure of victimization assessed was whether an adolescent ever experienced any overall cyberbully victimization techniques. Three forms of cyberbullying were assessed: through cellphone, text, or on-line. Each of these items were recoded so that zero represents no and one represents yes. An index of how many different methods an adolescent experienced was then created by combining responses to these three items. The variables in the index were relabeled so that zero represents experiencing no cyberbully techniques and three represents experiencing all cyberbully techniques.

\subsection{Methods}

For my research purposes I used univariate analysis that consists of frequency distributions and descriptive statistics. For my bivariate analysis I used a chi-square test to assess the relationship with the dependent variable, traditional bystander engagement, to the independent variables gender, social networking site victimization in the last 12 months, or if the adolescent is a Facebook, MySpace, or Twitter user. To determine if there is a relationship between either dependent variables, pro-social bystander engagement and traditional bystander engagement, and the independent variables, age, frequency of social networking site use, parental monitoring, perceptions of cruel on-line environment, witness pro-social behavior, witness joining in, witness ignoring, social networking site victimization in the last 12 months, and overall cyberbully victimization techniques a Pearson's correlation test was conducted. To assess whether there is a significant difference between pro-social bystander engagement and 
gender, Facebook, MySpace, or Twitter user, and social networking site victimization in the last 12 months t-test's were conducted. Finally for my multivariate analysis I conducted Ordinary Least Squares Regression tests to determine how much the independent variables influence the dependent bystander engagement variables. 


\section{CHAPTER 4}

\section{RESULTS}

\subsection{Univariate Analysis}

Table 1 presents the results for the dependent variable pro-social bystander engagement. Of the 531 adolescents sampled, the average pro-social bystander engagement score is $3.31+/-$ 1.89. Table 1 also presents the results for the dependent variable traditional bystander engagement. Of the 535 adolescents sampled, the average traditional bystander engagement score is $2.00+/-.94$.

Table 1 presents the results for the variable age. Of the 800 adolescents sampled the average age is $14.5+/-1.72$. Table 1 presents the results for the variable parental monitoring techniques used. Of the 459 adolescents sampled an average of $1.67+/-1.30$ parental monitoring techniques are used. Table 1 presents the results for the variable perceptions of cruel on-line environment. Of the 610 adolescents sampled, the average perceived the on-line environment to be cruel score is $1.41+/-.84$. Table 1 presents the results for the variable witness pro-social behavior on-line. Of the 535 adolescents sampled, the average witnessed pro-social behavior online score is $3.20+/-1.72$. Table 1 presents the results for the variable witness others joining in with bullying. Of the 538 adolescents sampled, the average witnessed others join in with the bullying score is $1.28+/-1.12$. Table 1 presents the results for the variable witness others ignoring the bullying. Of the 539 adolescents sampled, the average witnessed others ignoring bullying score is $2.34+/-.86$. 
Table 2 presents the results for the variable gender. Of the 800 adolescents sampled $51.4 \%$ are males. Table 2 presents the results for the variable social networking site use. Of the 614 adolescents sampled $5.4 \%$ stated they use social networking sites less often while the majority stated they used social networking sites several times a day at $40.1 \%$. Table 2 presents the results for the variable social networking site victimization in the last 12 months. Of the 614 adolescents sampled $15.1 \%$ stated they had been victimized in the last 12 months. Table 2 presents the results for the variable experienced overall cyberbully victimization techniques. Of the 798 adolescents sampled $86.6 \%$ stated that they had never experienced any techniques, while $2.6 \%$ stated they experienced all cyberbully victimization techniques. Table 2 presents the results for the variables Facebook user, MySpace user, and Twitter user. Of the 800 adolescents sampled 71.4\% stated they used Facebook, 18.7\% said they used MySpace, and finally, 9.5\% of adolescents said they used Twitter.

\subsection{Bivariate Analysis}

\subsubsection{Chi-Square (Table 3)}

The chi-square results show that females are less likely to practice traditional bystander engagement compared to men. More females have never practiced traditional bystander engagement at $10.7 \%$ compared to males at $6.8 \%$. More females practiced traditional bystander engagement only once in a while at $18 \%$ compared to men at $16.3 \%$. More females practice traditional bystander engagement sometimes at $42.6 \%$ compared to men at $35.7 \%$. Finally, fewer females practiced traditional bystander engagement frequently at $28.7 \%$ compared to men at $41.1 \%$. The statistics show that there is statistical significance $(\mathrm{p}<.05)$, for the comparison of the dependent variable traditional bystander engagement and the independent variable gender. 
The chi-square results show that adolescents who have experienced social networking site victimization in the last 12 months are less likely to practice traditional bystander engagement. More adolescents who stated they had been victimized in the last 12 months through a social networking sites are more likely to never practice traditional bystander engagement at $14.9 \%$ compared to those who have not been victimized in the last 12 months at 7.6\%. Adolescents who have been victimized in the last 12 months are less likely to once in a while practice traditional bystander engagement at $8 \%$ compared to those who have never experienced victimization at $19 \%$. Adolescents who have been victimized in the last 12 months are more likely to sometimes practice traditional bystander engagement at $46 \%$ compared to those who have not been victimized at $37.8 \%$. Finally, adolescents who were victimized in the last 12 months are less likely to practice traditional bystander engagement frequently at $31 \%$ compared to those who have not been victimized at $35.6 \%$. The statistics show that there is statistical significance $(\mathrm{p}<.05)$, for the comparison of the dependent variable traditional bystander engagement and the independent variable social networking site victimization in the last 12 months.

The chi-square results show that Facebook users are more likely to practice traditional bystander engagement compared to those who are not Facebook users. Those who are Facebook users are less likely to never practice traditional bystander engagement at $8.2 \%$ compared to those who do not use Facebook at $16.7 \%$. Adolescents who use Facebook are more likely to practice traditional bystander engagement once in a while at $18.4 \%$ compared to those who do not use Facebook at 2.8\%. Adolescents who use Facebook are less likely to practice traditional bystander engagement sometimes at $37.3 \%$ compared to adolescents who do not use Facebook at 63.9\%. Finally, adolescents who use Facebook are more likely to frequently practice traditional 
bystander engagement at $36.1 \%$ compared to those who do not use Facebook at $16.7 \%$. The statistics show that there is statistical significance $(\mathrm{p}<.001)$, for the comparison of the dependent variable traditional bystander engagement and the independent variable Facebook user.

The chi-square results show that MySpace users are more likely to practice traditional bystander engagement compared to those who are not MySpace users. Those who are MySpace users are less likely to never practice traditional bystander engagement at $7.4 \%$ compared to those who do not use MySpace at 9.2\%. Adolescents who use MySpace are more likely to practice traditional bystander engagement once in a while at $18 \%$ compared to those who do not use MySpace at $17.1 \%$. Adolescents who use MySpace are more likely to practice traditional bystander engagement sometimes at $46.7 \%$ compared to adolescents who do not use MySpace at 37\%. Finally, adolescents who use MySpace are less likely to frequently practice traditional bystander engagement at $27.9 \%$ compared to those who do not use MySpace at 36.7\%\%. The statistics show that there is no statistical significance $(\mathrm{p}=.186)$, for the comparison of the dependent variable traditional bystander engagement and the independent variable MySpace user.

The chi-square results show that Twitter users are more likely to practice traditional bystander engagement compared to those who are not Twitter users. Those who are Twitter users are less likely to never practice traditional bystander engagement at $4.1 \%$ compared to those who do not use Twitter at $9.5 \%$. Adolescents who use Twitter are less likely to practice traditional bystander engagement once in a while at $8.2 \%$ compared to those who do not use Twitter at $18.8 \%$. Adolescents who use Twitter are more likely to practice traditional bystander engagement sometimes at $50.7 \%$ compared to adolescents who do not use Twitter at $37.2 \%$. Finally, adolescents who use Twitter are more likely to frequently practice traditional bystander 
engagement at $37 \%$ compared to those who do not use Twitter at $34.4 \%$. The statistics show that there is statistical significance $(\mathrm{p}<.05)$, for the comparison of the dependent variable traditional bystander engagement and the independent variable Twitter user.

\subsubsection{Correlation (Table 4)}

To determine correlations between the dependent variable pro-social bystander engagement and each independent variable for Model 1, a Pearsons $\mathrm{R}$ Correlation test was conducted. Results show eight possible relationships, which are as follows. The frequency of social networking site use on pro-social bystander engagement was found to have a very weak positive relationship and is statistically significant $(\mathrm{r}=.09, \mathrm{p}<.05)$. Parental monitoring techniques used and pro-social bystander engagement was found to have a slightly moderate positive relationship and is statistically significant $(r=.17, \mathrm{p}<.001)$. Perceptions of a cruel on-line environment and pro-social bystander engagement was found to have a weak positive relationship and is statistically significant $(\mathrm{r}=.10, \mathrm{p}<.05)$. Witnessing others act in pro-social bystander engagement on-line and pro-social bystander engagement was found to have a moderate positive relationship and is statistically significant $(\mathrm{r}=.48, \mathrm{p}<.001)$. Witnessing others join in with the bullying and pro-social bystander engagement was found to have a weak positive relationship and is statistically significant $(r=.17, p<.001)$. Witnessing others ignore bullying and pro-social bystander engagement was found to have a weak positive relationship and is statistically significant $(\mathrm{r}=.12, \mathrm{p}<.01)$. Social networking site victimization in the last 12 months and pro-social bystander engagement was found to have a slightly moderate positive relationship and is statistically significant $(\mathrm{r}=.18, \mathrm{p}<.001)$. Experiencing overall cyberbully victimization techniques and pro-social bystander engagement was found to have a weak positive relationship and is statistically significant $(\mathrm{r}=.15, \mathrm{p}<.001)$. 
To determine if any correlations exist between the dependent variable traditional bystander engagement and the independent variables a Pearson's $\mathrm{R}$ correlation test was conducted. The results show three relationships, which are as follows. Witnessing others join in with the bullying and traditional bystander engagement was found to have a weak positive relationship and is statistically significant $(\mathrm{r}=.10, \mathrm{p}<.05)$. Witnessing others ignore bullying and traditional bystander engagement was found to have a slightly moderate relationship and is statistically significant $(\mathrm{r}=.25 \mathrm{p}<.001)$. Experiencing overall cyberbully victimization techniques and pro-social bystander engagement was found to have a weak negative relationship and is statistically significant $(\mathrm{r}=-.13, \mathrm{p}<.01)$.

\subsubsection{T-Test (Table 5, 6, 7)}

Table 5 shows the results for a t-test, which was conducted to evaluate the hypothesis that females are more likely to practice pro-social bystander engagement. Females do report higher instances of pro-social bystander engagement compared to males. The difference was statistically significant. A Cohen's D was performed (-0.24454) and determined that the difference was meaningful and did show a weak relationship in the sample. The findings suggest that there is a relationship between gender and pro-social bystander engagement.

Table 6 shows the results for a t-test, which was conducted to evaluate the hypothesis that adolescents who use Facebook are more likely to practice pro-social bystander engagement. Facebook users do not report higher instances of pro-social bystander engagement compared to those who do not use Facebook. The difference was not statistically significant and did not have a relationship. The findings suggest that there is not a relationship between using Facebook and pro-social bystander engagement. 
Table 6 shows the results for a t-test, which was conducted to evaluate the hypothesis that adolescents who use MySpace are less likely to practice pro-social bystander engagement. MySpace users do not report lower instances of pro-social bystander engagement compared to those who do not use MySpace. The difference was not statistically significant and did not have a relationship. The findings suggest that there is not a relationship between using MySpace and pro-social bystander engagement.

Table 6 shows the results for a t-test, which was conducted to evaluate the hypothesis that adolescents who use Twitter are less likely to practice pro-social bystander engagement variable. Twitter users do report lower instances of pro-social bystander engagement compared to those who do not use Twitter. The difference was statistically significant. A Cohen's D was performed (.364917) and determined the difference was meaningful and did show a moderate relationship in the sample. The findings suggest that there is a relationship between using Twitter and pro-social bystander engagement.

Table 7 shows the results for a t-test, which was conducted to evaluate the hypothesis that adolescents who have been victimized in the last twelve months on a social networking site are more likely to practice pro-social bystander engagement. Adolescents who have been victimized in the last twelve months on a social networking site do report higher instances of pro-social bystander engagement compared to those who were not victimized in the last twelve months. The difference was statistically significant. A Cohen's D was performed (.606061) and determined the difference was meaningful and did show a moderate relationship in the sample. The findings suggest that there is a relationship between those who have been victimized in the last twelve months on a social networking site and pro-social bystander engagement. 


\subsection{Multivariate Analysis}

Two regression models were run to explore the factors that may predict each bystander outcome (ie, pro-social bystander engagement vs traditional bystander engagement). Based on existing cyberbullying research, each model included age, gender, frequency of social networking site use, Facebook, MySpace, or Twitter users, parental monitoring techniques, perceptions of cruel on-line environment, witness pro-social bystander behavior on-line, witness joining in with bullying, witness ignoring the bullying, victimization on a social networking site in the last 12 months, and experiencing overall cyberbully victimization techniques.

\subsubsection{Tests for Assumptions}

For model 1 the dependent variable, does bystander act in a pro-social manner was not normally distributed. There was a total of 413 participants. Tests of residuals suggests that this might be an issue. However, none of the independent variables were correlated over .70. Tests for outliers were conducted. The maximum found in the Mahalonobis distance test was 50, but the maximum for the Cook's distance test was less than 1 . Outliers were less than $1 \%$ of the total sample and therefore no outliers were removed.

The total sample is 414 for model 2. This dependent variable, does bystander engage in traditional bystander engagement was not normally distributed. Tests of residuals suggests that this might be an issue. However, none of the independent variables were correlated over .70. Tests for outliers were conducted. The maximum found in the Mahalonobis distance test was 49, but the maximum for the Cook's distance test was less than 1 . Outliers were less than $1 \%$ of the total sample and therefore no outliers were removed. 


\subsubsection{Model 1}

Table 8 presents the results for the multiple regression analysis that was conducted for model 1 to evaluate how well the variables (age, gender, frequency of social networking site use, Facebook, MySpace, or Twitter users, parental monitoring techniques, perceptions of cruel online environment, witness pro-social bystander engagement on-line, witness bystanders joining in with the bully, witness bystanders ignoring the bullying, SNS victimization in the last twelve months, and overall cyberbully victimization) predict pro-social bystander engagement.

For each year older the adolescent is they will have a .09 increase in pro-social bystander engagement but the beta was not statistically significant. For gender, females have a .32 increase in practicing pro-social bystander engagement compared to males but this was not statistically significant. Frequency of social networking site use was found to have a .04 decrease of adolescent's willingness to practice pro-social bystander engagement. Those who use Facebook have a .48 decrease in practicing pro-social bystander engagement compared to those who do not use Facebook. This was not statistically significant. Those who use MySpace have a .19 increase in using pro-social bystander engagement compared to those who do not use MySpace. This was not statistically significant. Those who were Twitter users have a .21 increase in practicing pro-social bystander engagement compared to those who do not use Twitter. This was not statistically significant. For each increase in parental monitoring technique used there is a .19 increase in practicing pro-social behavior and is statistically significant. Those who perceived a cruel on-line environment had a .13 increase in practicing pro-social bystander engagement, but was not statistically significant. 
Those who witness others practicing pro-social bystander engagement on-line have a .49 increase in practicing pro-social bystander engagement and this was statistically significant at $\mathrm{p}<.001$. Adolescents who witnessed others practice traditional bystander engagement by joining in were found to have a 10 increase in pro-social bystander engagement but was not statistically significant. Those adolescents who witnessed others practice traditional bystander engagement by ignoring the findings show that they have a .03 decrease in practicing pro-social bystander engagement. This was not statistically significant. Those who had been victimized in the last twelve months on a social networking site showed a .16 decrease in pro-social bystander engagement. This was not statistically significant. Those who had suffered overall cyberbully victimization techniques have a .29 increase in pro-social bystander engagement and was statistically significant at $\mathrm{p}<.05$. The adjusted $\mathrm{R}^{2}$ for model 1 is .27 so that about $27 \%$ of the variation in pro-social behavior is explained by these variables.

\subsubsection{Model 2}

Table 9 presents the results for the multiple regression analysis that was conducted for model 2 to evaluate how well the variables (age, gender, frequency of social networking site use, Facebook, MySpace, or Twitter users, parental monitoring techniques, perceptions of cruel online environment, witness pro-social engagement on-line, witness bystanders joining in with the bully, witness bystanders ignoring the bullying, SNS victimization in the last twelve months, and overall cyberbully victimization) predict traditional bystander engagement.

The older one is they will have a .01 decrease in traditional bystander engagement for each year increase in age. This was not statistically significant. For gender, females will have a .15 increase in practicing traditional bystander engagement compared to males but this was not 
statistically significant. Frequency of social networking site use was found to have a .03 increase of adolescent's willingness to practice traditional bystander engagement. This was not statistically significant. Those who use Facebook have a .38 increase in practicing traditional bystander engagement compared to those who do not use Facebook. This was not statistically significant. Those who use MySpace will have a .06 increase in practicing traditional bystander engagement compared to those who do not use MySpace. This was not statistically significant. Twitter users were found to have a .28 increase in practicing traditional bystander engagement compared to those who do not use Twitter. This was statistically significant at $\mathrm{p}<.05$.

For each increase in parental monitoring technique used there is a .06 decrease in practicing traditional bystander engagement but was not statistically significant. Those who perceived behavior on-line to be cruel had a .07 increase in practicing traditional bystander engagement, but was not statistically significant. Those who witness others practicing pro-social bystander engagement on-line have a .02 decrease in practicing traditional bystander engagement. For adolescents who witnessed others practice traditional bystander engagement by joining in were found to have a .04 increase in traditional bystander engagement but was not statistically significant. Adolescents who witnessed others practice traditional bystander engagement by ignoring, the findings show that they have a .29 increase in practicing traditional bystander engagement. This variable was statistically significant at $\mathrm{p}<.001$. Those who had been victimized in the last twelve months on a social networking site showed a .08 increase in traditional bystander engagement, but was not statistically significant. Those who had suffered overall cyberbully victimization techniques were shown to have a .14 decrease in ignoring for traditional bystander engagement. This variable is statistically significant at $\mathrm{p}<.05$. The adjusted 
$\mathrm{R}^{2}$ for model 2 is .10 so that about $10 \%$ of the variation in traditional bystander engagement is explained by these variables. 


\section{CHAPTER 5}

\section{CONCLUSION}

\subsection{Discussion}

Electronic aggression or cyberbullying has been defined by the Center for Disease Control and Prevention (Hertz and David-Ferdon, 2008) as bullying that consists of various elements, from teasing and telling lies to spreading rumors or making threatening comments. These behaviors are all done through the modes of communication adolescents utilize on a daily basis. E-mails, text messaging, instant messaging, and or chat rooms are just a few of the outlets cyberbullies tend to victimize through (p. 3). As if those were not enough, Mitchell, et. al., (2011) found that cyberbullies tend to use a combination of elements at once to harass other adolescents. This relentless and seemingly endless barrage of attacks raises concern for the adolescents on the receiving end.

Bystanders are present in the majority of cyberbullying instances. The modes of engagement for bystanders include simply watching or ignoring the incident (i.e., traditional bystanding), joining in or supporting the bullying in some way, and lastly standing up by defending the victim or challenging the bully (i.e., pro-social bystander engagement). The focus of this exploratory study, which was based on Darley and Latane's 1968 Bystander Intervention model, was to examine whether the original model would be applicable to the cyber sphere. To achieve this goal it was important to understand what influences different modes of bystander engagement. This study is among the first to explore bystander engagement in the cyber sphere and is unique in trying to uncover factors that may influence different modes of bystander engagement in relation to cyberbullying. 
The first research question explored in this research was how common is cyberbullying on social networking sites frequented by youth? Based on the findings of the current study, it appears that $13 \%$ of adolescents have experienced at least one form of cyberbully victimization through any electronic medium. Additionally, $15 \%$ of adolescents stated that someone had been cruel to them in the last 12 months on a social networking site. Finally, $41 \%$ of adolescents stated they witnessed others acting cruel on social networking sites. These findings are consistent with previous research done by Lenhart et. al., (2011) who also found that about $15 \%$ of adolescents had experienced cyberbullying. Unfortunately, the current research was unable to explore how common cyberbullying is on specific social networking sties which is an avenue that should be evaluated through future research.

The second research question explored in this study was how do youth react to cyberbullying on popular social networking sites? The findings show that many adolescents are acting pro-socially, with $61 \%$ stating that they sometimes to frequently told the bully to stop and $62 \%$ of adolescents stated they sometimes to frequently defended the victim. Compared to previous research on traditional bullying by Lenhart et. al., (2011), this finding suggests the possibility that there are higher instances of pro-social bystander engagement in the cyber realm. It is worth noting, however, that the current research also showed that the majority of adolescents (74\%) reported acting as traditional bystanders reporting they sometimes to frequently ignored the cyberbullying, a rate also consistent with prior research (Lenhart et. al., 2011). Because youth were found to engage in both pro-social and traditional ways, further research assessing the specific characteristics of a cyberbullying incident which elicits one form of engagement or the other is warranted. What is potentially promising in the current research, nonetheless, is the 
finding that only $9 \%$ of adolescents stated that they sometimes to frequently joined in with the cyberbully.

The third research question in this study explored factors that may predict which adolescents engage in traditional bystanding and which participate in pro-social bystander engagement. Based on model 1, the factors that were shown to influence pro-social bystander engagement were witnessing others act in a pro-social manner, having parents who monitor their cyber activities, and having personally experienced overall cyberbully victimization. Based on model2, it was found that witnessing others ignoring cyberbullying, being a Twitter user, and having personally been a victim of overall cyberbullying techniques were factors that influence traditional bystander engagement. Therefore the current research was able to determine some initial factors that may influence different modes of bystander engagement. Across models, the strongest influencers on modes of engagement appeared to be perceived group norms and personal experiences of cyberbullying. Both of these factors may also influence how adolescents define cyberbullying, a prerequisite for action. According to Lenhart et. al., (2011), interaction on social networking sites between adolescents may seem like bullying to an adult, but to the adolescents it could be viewed as typical banter. Further research on perceived norms of on-line behavior is suggested.

Several additional factors that approached significance are also worth noting, due to their potential influence on the mode of bystander engagement an adolescent chooses. First, age was found to be approaching significance for practicing pro-social bystander engagement, with adolescents increasing their likelihood of enacting pro-social behaviors with age. The direction of this finding contradicts previous research conducted by Salmivalli and Voeten (2004), who found that as adolescents get older they prefer to ignore traditional bullying. Therefore, further 
research is needed to more fully assess the possible relationship of age with pro-social engagement. A second factor approaching significance for pro-social bystander engagement was gender, with the findings suggesting females may be more likely to participate in pro-social bystander engagement. This finding is consistent with both the bivariate results reported in the results of this study and with previous research. For example, Ahmed (2008) found that "girls were more likely to participate in bullying prevention" (p. 209). It is suggested that the role of gender in bystander engagement in the context of cyberbullying should be explored further.

Two variables, Facebook use and parental monitoring techniques, approached significance in relation to practicing traditional bystander engagement. Both findings contradicted the hypothesis of the current study which anticipated that Facebook users would be less likely to ignore cyberbullying and that parental monitoring would increase the likelihood of ignoring. Unfortunately, there are no prior studies that have researched how adolescents respond to cyberbullying on Facebook. The findings on parental monitoring techniques, on the other hand, were found to be consistent with previous research that suggest parents are instructing their children to stay out of bullying incidents (Wilson-Simmons et. al., 2006).

The final research question explored in the current study was whether bystander engagement outcomes vary from Facebook, to MySpace, to Twitter. The research was only partially able to answer this question due to the inability to measure how much cyberbullying occurs on each social networking site specifically. The regression results suggest that Twitter and Facebook users, as opposed to non-users, engage in traditional bystanding behavior on-line. Future research should further explore specific acts of cyberbulling experienced on each site as well as further explore potential bystander responses on both the standard (Facebook, MySpace, Twitter) and emerging social networking sites such as Instagram, Tumblr, and Snap Chat. It is 
possible that rates of cyberbullying and reactions to cyberbullying vary across different social networking sties.

In conclusion, this study identifies potential elements that may lead to a better understanding of the various influences behind bystander behavior in reaction to cyberbullying episodes on social network sites. The findings from each model aid initial understandings of the nature and actions of bystander responses in regards to cyberbullying. However, considering the low amount of variance accounted for in each model, several other influencing variables remain to be discovered. Continuing this line of research is important for not only understanding what motivates adolescents when they choose a certain type of engagement but results may also suggest avenues for effective prevention strategies when combating cyberbullying as a whole.

\subsection{Limitations}

The findings of this study are limited by several factors, the first being the sample size. The current study consisted of a maximum of 800 respondents. Once the weights were applied to generalize the sample to population parameters the sample size for this study was essentially cut to almost half. Two variables approaching significance, gender and parental monitoring techniques used, would likely have been significant had the sample size been larger. Additionally, it was beyond the scope of this research to explore what factors influence adolescents who join in with the cyberbully because the sample size was so small. While the Pew data used in the current study drew form a national sample, larger national data sets are needed to more fully understand the role of bystander engagement on-line.

A second limitation of the data is the inability to assess where cyberbullying is occurring in reference to different social networking sites. The questions that remain to be answered here 
is whether cyberbullying is happening more on Facebook, MySpace, or possibly Twitter, or equally across all three mediums? As mentioned previously, there is also the possibility that other emerging social networking sites are being used as a venue for cyberbullying. Exposing which sites have higher incidents will in turn allow for tailoring interventions toward specific sites.

A third limitation is the speed at which technology changes and evolves. Research takes time and at times it seems impossible to keep up with. Technology can change in so many ways in as little as a year alone. With new devices for communicating, from apps that make our lives easier to new and growing communication sites, advances in technology continually evolve making research on the various aspects related to the cyber sphere difficult. Timely research that is able to keep up with the latest technological trends is crucial to maintaining an effective plan to reduce and prevent cyberbullying.

Despite these limitations, the current research suggests avenues for prevention of cyberbullying based on techniques currently used to combat in person bullying. My research shows that witnessing peer actions influence individual actions and that a victim may follow different norms of engagement than a non-victim. Therefore, prevention efforts should focus on discovering perceived norms within a school or neighborhood, discussing potential consequences (positive or negative) for breaking existing peer norms, and then work with adolescents to develop ideal norms and the steps that can be taken to engage in pro-social behaviors to either directly or indirectly intervene in the face of cyberbullying.

Previous research suggests that including adolescents in developing prevention options, particularly interventions geared at changing norms, is imperative. For example, it is of great 
importance to understand what the adolescents feel can help with the problem of traditional bullying. Ybarra and Mitchell, (2004), found that adolescents believed student discussions were important in determining rules, educational initiatives, and norms for behaviors. The same is true of intervening in cyberbulllying. Several studies found that students prefer anti-bully interventions that include teacher involvement and that younger children are more willing to accept a teacher's authority than a peer's, so making a teacher aware of instances of cyberbullying may be important in programming geared toward younger youth (Rigby et, al., 2004; Peplar et. al., 2004; Richard et, al., 2011; Paul, Smith, and Blumberg, 2012).

Youth also have the ability to influence and create policy and change. Because adolescents are the ones whose lives are intertwined in the cyber world, it would be the adolescents who best understand the functions of that world and how to combat the negative actions that may take place there. That is why it is of utmost importance to keep the direct lines of communication with the adolescent open so that adults do not succumb to the generation on gap and are able to act on the direct experiences of the adolescent (Cheng, Chen, Ho, and Cheng, 2011; Mishna et. al., 2009; Mitchell et. al., 2007). Adolescents should always be included in the advocacy and campaign planning. They should be treated as a resource not just part of the problem (Ybarra and Mitchell, 2004). 
BIBLIOGRAPHY 


\section{BIBLIOGRAPHY}

Ahlfors, Rebecca. 2010. "An Internet Based Catalog of Cyberbullying Websites". UMT Dissertation Publishing, ProQuest LLC.

Ahmed, Eliza. 2008. "Stop it, that's Enough: bystander Intervention and its Relationship to School Connectedness and Shame Management".

Vulnerable Children and Youth Studies 7(3), 203-213.

Ahmed, Eliza and Valerie Braithwaite. 2004. "Bullying and Victimization: Cause for Concern for Both Families and Schools". Social Psychology of Education 7, $35-54$.

Ahn, June. 2011. "The Effect of Social Network Sites on Adolescents' Social and Academic Development: Current Theories and Controversies". Journal of the American Society for Information Science and Technology 62(8), 1435-45.

Banyard, Victoria L. 2008. "Measurement and Correlates of Prosocial Bystander Behavior: The Case of Interpersonal Violence". Violence and Victims 23(1), 83-97.

Banyard, Victoria L., Mary M. Moynihan, and Maria T. Crossman. 2009. "Reducing Sexual Violence on Campus: The role of Student Leaders as Empowered Bystanders". Journal of College Student Development 50(4), 446-57.

Banyard, Victoria L., Elizabethe G. Plante, and Mary M. Moynihan. 2004. "Bystander Education: Bringing A Broader Community Perspective To Sexual Violence Prevention”. Journal of Community Psychology 32(1), 61-79.

Barhight, Lydia R., Julie A. Hubbard, and Christopher T. Hyde. 2013. “Children's Physiological and Emotional Reactions to Witnessing Bullying Predict Bystander Intervention". Child Development 84(1), 375-90. 
Hertz, M. and C. David-Ferdon. 2008. "Electronic Media and Youth Violence: A CDC Issue Brief for Educators and Caregivers. Atlanta GA: Centers for Disease Control. Retrieved on March 2013 at:

http://www.ncjrs.gov/App/publications/astract.aspx?ID=249597

Cheng, Ying-Yao, Li-Ming Chen, Hsiao-Chi Ho, and Chih-Ling Cheng. 2011. "Definitions of School Bullying in Taiwan: A Comparison of Multiple Perspectives". School Psychology International 32(3), 227-43.

Choi, Sumi and Young Il Cho. 2012. "Influence of Psychological and Social Factors on bystanders' Roles in School bullying Among Korean-American Students in the United States". School Psychology International 1-15.

Coloroso, Barabara. 2011. "Bully, Bullied, Bystander and Beyond: How Students Choose a New Role". Teaching Tolerance 39, 51-53.

Cowie, Helen. 2000. "Bystanding or Standing By: Gender Issues in Coping With Bullying in English Schools". Aggressive Behavior 26, 85-97.

Critelli, Joseph W. and Kathy W. Keith. 2003. "The Bystander Effect and the Passive Confederate: On the Interaction Between Theory and Method".

The Journal of Mind and Behavior 24(3, 4), 255-64.

Dahl, Julia. 2013. "Steubenville Rape Update: Bystanders, Coaches, and Parents will now be the Focus of Ohio AG Mike Dewine". Retrieved on February 2013 at:

http://www.cbsnews.com/8301-504083_162-57574936-504083/steubenville-rapeupdate-bystanders-coaches-and-parents-will-now-be-focus-of-ohio-ag-mikedewine/

Darley, John M. and Bibb Latane. 1968. "Bystander Intervention in Emergencies: Diffusion of Responsibility". Journal of Personality and Social Psychology 8(4), 377-83.

Dempsey, Allison L., Michael L. Sulkowski, Rebecca Nichols, and Eric A. Storch. 2009. "Differences Between Peer Victimization in Cyber and Physical Settings and Associated Psychosocial Adjustment in Early Adolescence”. Psychology in the Schools 46(10), 962-72. 
Dunn, Shelagh Tara May. 2009. "Upstanders: Student Experiences of Intervening to Stop Bullying”. University of Alberta, Edmonton, Alberta.

Erdur-Baker, Ozgur. 2010. "Cyberbullying and its Correlation to Traditional Bullying, Gender and Frequent and Risky Usage of Internet-Mediated Communication Tools". New Media and Society 12(1), 109-25.

Espelage, Dorothy, Harold Green, and Joshua Polanin. 2011. "Willingness to Intervene in Bullying Episodes Among Middle School Students: Individual and Peer-Group Influences". The Journal of Early Adolescence 17, 1-26.

Espinoza, Guadalupe and Jaana Juvonen. 2011. "The Pervasiveness, Connectedness, and Intrusiveness of Social Network Site Use Among Young Adolescents". Cyberpsychology, Behavior, and Social Networking 14(12), 70509.

Evers, Kerry E., James O. Prochaska, Deborah F. Van Marter, Janet L. Johnson, and Janice M. Prochaska. 2008. "Transtheoretical-Based Bullying Prevention Effectiveness Trials in Middle Schools and High Schools" Educational Research 49(4), 397-414.

Gini, Gianluca, Paolo Albiero, Beatrice Benelli, Gianmarco Altoe. 2008. "Determinants of Adolescents' Active Defending and Passive Bystanding Behavior in Bullying" Journal of Adolescence 31, 93-105.

Gini, Gianluca, Tiziana Pozzoli, Francesco Borghi, and Lara Franzoni. 2008. "The Role of Bystanders in Students' Perception of Bullying and Sense of Safety". Journal of School Psychology 46, 617-38.

Hinduja, Sameer and Justin W. Patchin. 2008. "Cyberbullying: An Exploratory Analysis of Factors Related to Offending and Victimization". Deviant Behavior 29(2), 129-56.

2010. "Bullying, Cyberbullying, and Suicide". Archives of Suicide Research 14, 206-21. 
Hudson, James M. and Amy S. Bruckman. 2004. "The Bystander Effect: A Lens for Understanding Patterns of Participation”. The Journal of the Learning Sciences 13(2), 165-95.

Jackson, Margaret, Wanda Cassidy, and Karen N. Brown. 2009. "You Were Born Ugly and You'll Die Ugly too: Cyber-bullying as Relational Aggression". Technology and Social Media (Special Issue, Part 1) 15(2), Retrieved on February 2012 at: ugly-and-youl-die-ugly-too-cyberbullying-relational-aggression

Jerome, Laurence and Al Segal. 2003. "Bullying by Internet (to the Editor)". Journal of the American Academy of Child and Adolescent Child Psychology 42(7), 751.

Kowalski, Robin M. and Susan P. Limber. 2007. "Electronic Bullying among Middle School Students". Journal of Adolescent Health 41, S22-S30.

Laner, Mary R., Mary H. Benin, and Nicole A. Ventrone. 2001. "Bystander Attitudes toward Victims of violence: Who's Worth Helping?" Deviant Behavior 22, 23-42.

Latane, Bibb and John M. Darley. 1970 "The Unresponsive Bystander: Why Doesn't He Help?" New York, New York: Meredith Corporation.

Law, Danielle M., Jennifer D. Shapka, Shelley Hymel, Brent F. Olson, and Terry Waterhouse. 2012. The Changing Face of Bullying: An Empirical Comparison Between Traditional and Internet Bullying and Victimization". Computers in Human Behavior 28, 226-32.

Lee, Sook-Jung and Young-Gil Chae. 2007. "Children's Internet Use in a Family Context: Influence on Family Relationships and Parental Mediation". CyberPsychology and Behavior 10(5), 640-44.

Lenhart, Amanda, Mary Madden, Aaron Smith, Kristen Purcell, Kathryn Zickuhr, and Lee Rainie. 2011. "Teens, Kindness and Cruelty on Social Network Sites". Pew Research Center's Internet and American Life Project. 
Li, Qing. 2006. "Cyberbullying in Schools: A Research of Gender Differences". School Psychology International 27(2), 157-70.

Liau, Albert Kienfie, Angeline Khoo, and Peng Hwa Ang. 2008. "Parental Awareness and Monitoring of Adolescent Internet Use". Current Psychology 27, 217-33.

Lodge, Jodie and Erica Frydenberg. 2005. "The Role of Peer Bystanders in School Bullying: Positive Steps toward Promoting Peaceful Schools" Theory and Practice 44(4), 329-336.

Lwin, May O., Benjamin Li, and Rebecca P. Ang. 2012. "Stop Bugging Me: An Examination of Adolescents' Protection Behavior Against Online Harassment". Journal of Adolescence 35, 31-41.

Madlock, Paul E. and David Westerman. 2011. "Hurtful Cyber-Teasing and Violence: Who's Laughing Out Loud"? Journal of Interpersonal Violence 26(17), 3542-60.

Markey, P.M. 2000. "Bystander Intervention in Computer-Mediated Communication". Computers in Human Behavior 16, 183-88.

McNamee, Abigail and Mia Mercurio. 2008. "School-Wide Intervention in the Childhood Bullying Triangle". Childhood Education 84(6), 370-78.

Mesch, Gustavo S. 2009. "Parental Mediation, Online Activities, and Cyberbullying". CyberPsychology and Behavior 12(4), 387-393.

Mishna, Faye, Michael Saini, and Steven Solomon. 2009. "Ongoing and Online: Children and Youth's Perceptions of Cyber Bullying". Children and Youth Services Review 31, 1222-28.

Mitchell, Kimberly J., David Finkelhor, Janis Wolak, Michele L. Ybarra, and Heather Turner. 2011. "Youth Internet Victimization in a Broader Victimization Context". Journal of Adolescent Health 48, 128-34. 
Mitchell, Kimberly J., Janis Wolak, and David Finkelhor. 2007. "Trends in Youth Reports of Sexual Solicitations, harassment and Unwanted Exposure to Pornography on the Internet”. Journal of Adolescent Health 40, 116-26.

Obermann, Marie-Louise. 2011. "Moral Disengagement Among Bystanders to School Bullying”. Journal of School Violence. 10, 239-57.

Oh, Insoo and Richard J. Hazler. 2009. "Contributions of Personal and Situational Factors to Bystanders' Reactions to School Bullying”. School Psychology International 30, 291-310.

Patchin, Justin W. and Sameer Hinduja. 2006. "Bullies Move Beyond the Schoolyard". Youth Violence and Juvenile Justice 4(2), 148-69.

Paul, Simone, Peter K. Smith, and Herbert H. Blumberg. 2012. "Revisiting Cyberbullying in Schools Using the Quality Circle Approach". School Psychology International 33, 492-504.

Pepler, Debra, Peter K. Smith, and Ken Rigby. 2004 Looking Back and Looking Forward: Implications for Making Interventions Work Effectively. In Bullying in Schools: How Successful can Interventions Be? Edited by Peter K. Smith, Debra Pepler, and Ken Rigby. 2004. Cambridge University Press.

Pozzoli, Tiziana, Gianluca Gini, and Alessio Vieno. 2012. "The Role of Individual Correlates and Class Norms in Defending and Passive Bystanding Behavior in Bullying: A Multilevel Analysis". Child Development 83(6), 1917-31.

Princeton Survey Research Associates International for the Pew Research Centers Internet and American Life Project Teens and Digital Citizenship Survey 2011. Retrieved on September 2012 at: http://www.pewinternet.org/SharedContent/Data-Sets/2011/July-2011-Teens-and-Online-Behavior.aspx

Pujazon-Zazik, Melissa and M. Jane Park. 2010. "To Tweet, or Not to Tweet:Gender Differences and Potential Postive and Negative Health Outcomes of Adolescents' Social Internet Use". American Journal of Men's Health 4(1), 7785 . 
Raskauskas, Juliana and Ann D. Stoltz. 2007. "Involvement in Traditional and Electronic Bullying Among Adolescents". Developmental Psychology 43(3), 56475.

Rigby, Ken, Peter K. Smith, and Debra Pepler. 2004. Working to Prevent School Bullying: Key Issues. In Bullying in Schools: How Successful can Interventions Be? Edited by Peter K. Smith, Debra Pepler, and Ken Rigby. 2004. Cambridge University Press.

Richard, Jacques F., Barry H. Schneider, and Pascal Mallet. 2011. "Revisiting the Whole-School Approach to Bullying: Really Looking at the Whole School". School Psychology International 33, 263-84.

Salmivalli, Christina. 2010. "Bullying and the Peer Group: A Review". Aggression and Violent Behavior 15, 112-20.

Salmivalli, Christina and Marinus Voeten. 2004. "Connections Between Attitudes, Group Norms, and Behavior in Bullying Situations" International Journal of Behavioral Development 28, 246-58.

Schneider, Shari Kessel, Lydia O’Donnell, Ann Stueve, and Robert W. S. Coulter. 2012. "Cyberbullying, School Bullying, and Psychological Distress: A Regional Census of High School Students". American Journal of Public Health 102(1), 171-77.

Sinclair, Katerina O., Sheri Bauman, Paul Poteat, Brian Koenig, and Stephen T.Russell. 2012. "Cyber and Bias-based Harassment: Associations With Academic, Substance Use, and Mental health Problems". Journal of Adolescent Health 1, 1-3.

Smith, Peter, Jess Mahdavi, Manuel Carvalho, and Neil Tippett. 2006. "An Investigation into Cyberbullying, its Forms, Awareness and Impact, and the Relationship Between Age and Gender in Cyberbullying". Research Brief, Brief No: RBX03-06. Retrieved on January 2013 at: https://www.education.gov.uk/publications/eOrderingDownload/RBX03-06.pdf 
Stueve, Ann, Kimberly Dash, Lydia O’Donnell, Parisa Tehranifar, Renee WilsonSimmons, Ronald G. Slaby, and Bruce G. Link. 2006. "Rethinking the Bystander role in School violence Prevention". Health Promotion Practice 7(1), 117-24.

Thornberg, Robert, Laura Tenenbaum, Kris Varjas, Joel Meyers, Tomas Jungert, and Gina Vanegas. 2012. "Bystander Motivation in Bullying Incidents:

to Intervene or Not to Intervene?". Western Journal of Emergency Medicine 8(3), 247-52.

Tokunaga, Robert S. 2010. "Following You Home from School: A Critical Review and Synthesis of Research on Cyberbullying Victimization". Computers in Human Behavior 26, 277-87.

Twemlow, Stuart W. 2008. "Assessing Adolescents Who Threaten Homicide in Schools: A Recent Update”. Clinical Social Work Journal 36, 127-29.

Twyman, Kimberly, Conway Saylor, Lloyd Adam Taylor, and Cadie Comeaux. 2010. "Comparing Children and Adolescents Engaged in Cyberbullying to Matched Peers". Cyberpsychology, Behavior, and Social Networking 13(2), 195 99.

Valkenburg, Pattie M. and Jochen Peter. 2009. "Social Consequences of the Internet for Adolescents: A Decade of Research". Current Directions in Psychological Science 18(1)1-5.

Vandebosch, Heidi and Katrien Van Cleemput. 2009. "Cyberbullying Among Youngsters: Profiles of bullies and Victims". New Media and Society 11(8), 1349-71.

Wang, Jing, Ronald J. Iannotti, and Tonja R. Nansel. 2009. "School Bullying Among Adolescents in the United States: Physical, Verbal, Relational, and Cyber". Journal of Adolescent Health 45, 368-75.

Williams, Kirk R. and Nancy G. Guerra. 2007. "Prevalence and Predictors of Internet Bullying”. Journal of Adolescent Health 41, S14-21. 
Wilson-Simmons, Renee, Kimberly Dash, Parisa Tehranifar, Lydia O'Donnell, and Ann Stueve. 2006. "What Can Student Bystanders do to Prevent School Violence? Perceptions of Students and School Staff”. Journal of School Violence 5(1), 43-62.

Wolak, Janis, Kimberly J. Mitchell, and David Finkelhor. 2007. "Does Online Harassment Constitute Bullying? An Exploration of Online Harassment by Known Peers and Online-Only Contacts”. Journal of Adolescent Health 41, S51S58.

Ybarra, Michele L., Cheryl Alexander, and Kimberly J. Mitchell. 2005. "Depressive Symptomatology, Youth Internet Use, and Online Interactions: A National Survey". Journal of Adolescent Health 36, 9-18.

Ybarra, Michele L., Marie Diener-West, and Philip J. Leaf. 2007. "Examining the Overlap in Internet Harassment and School bullying: Implications for School Intervention”. Journal of Adolescent Health 41, S42-S50.

Ybarra, Michele L. and Kimberly J. Mitchell. 2004. "Online Aggressor/Targets, Aggressors, and Targets: A Comparison of Associated Youth Characteristics". Journal of Child Psychology and Psychiatry 45(7), 1308-16.

Ybarra, Michele L., Kimberly J. Mitchell, Janis Wolak, and David Finkelhor. 2006. "Examining Characteristics and Associated Distress Related to Internet Harassment: Findings From the Second Youth Internet Safety Survey”. Pediatrics 118, 1169-77. 
APPENDIX 


\section{APPENDIX}

\section{Figure 1:}

\section{MODEL 1}

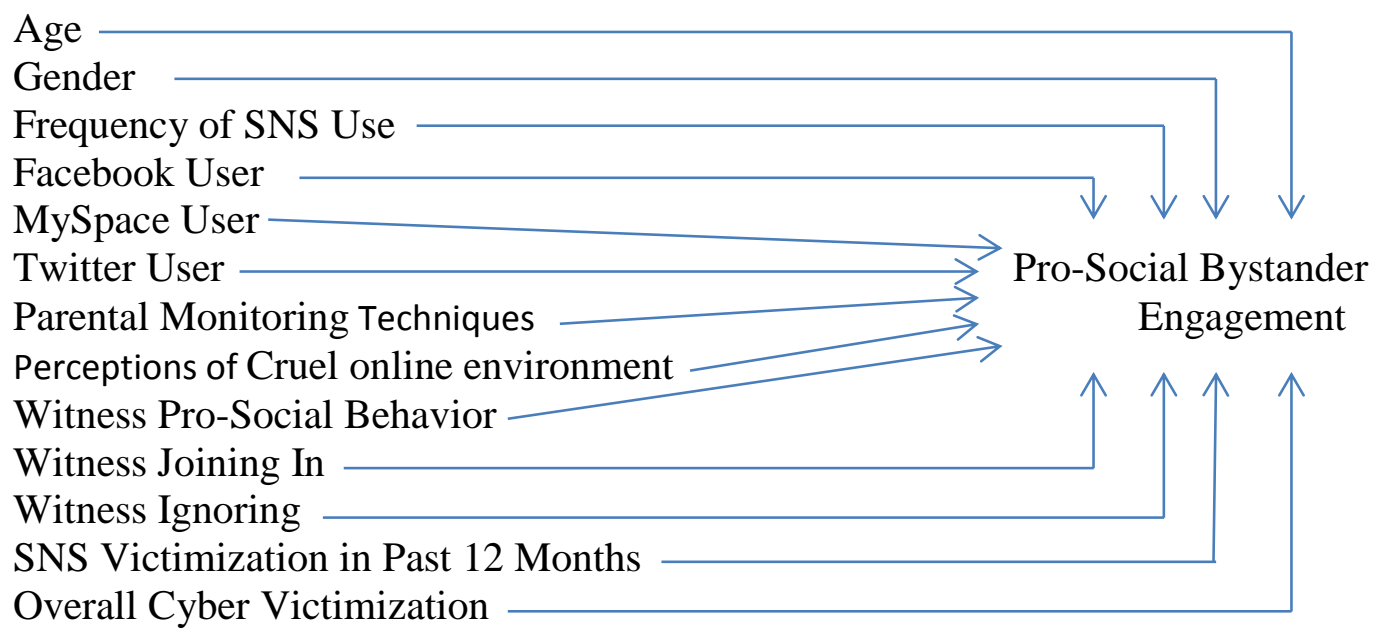

\section{Figure 2:}

\section{MODEL 2}

Age

Gender

Frequency of SNS Use

Facebook User

MySpace User

Twitter User

Parental Monitoring Techniques

Perceptions of Cruel online environment

Witness Pro-Social Behavior

Witness Joining In

Witness Ignoring

SNS Victimization in Past 12 Months

Overall Cyber Victimization 
Table 1: Univariate Analysis Descriptives

\begin{tabular}{|c|c|c|c|c|c|c|}
\hline \multicolumn{2}{|l|}{ Variables } & $\mathbf{N}$ & Median & Mean & $\mathrm{SD}+/-$ & Range \\
\hline \multicolumn{2}{|l|}{ Age } & 800 & 14.5 & 14.5 & 1.72 & $12-17$ \\
\hline \multicolumn{7}{|c|}{ Parental Monitoring } \\
\hline \multicolumn{2}{|c|}{ Techniques } & 459 & 2 & 1.67 & 1.30 & $0-4$ \\
\hline \multicolumn{7}{|l|}{ Perceptions of Cruel } \\
\hline \multicolumn{2}{|c|}{ On-line Environment } & 610 & 2.5 & 1.41 & .84 & $0-3$ \\
\hline \multicolumn{7}{|c|}{ Witness Pro-Social } \\
\hline \multicolumn{2}{|l|}{ Behavior } & 535 & 3 & 3.20 & 1.72 & $0-6$ \\
\hline \multicolumn{2}{|l|}{ Witness Joining In } & 538 & 1.5 & 1.28 & 1.12 & $0-3$ \\
\hline \multicolumn{2}{|c|}{ Witness Ignoring } & 539 & 1.5 & 2.34 & .86 & $0-3$ \\
\hline \multicolumn{7}{|c|}{ Pro-Social Bystander } \\
\hline \multicolumn{2}{|l|}{ Engagement } & 531 & 3 & 3.31 & 1.89 & $0-6$ \\
\hline \multicolumn{7}{|c|}{ Traditional Bystander } \\
\hline \multicolumn{2}{|c|}{ Engagement } & 535 & 1.5 & 2.00 & .94 & $0-3$ \\
\hline \multicolumn{7}{|c|}{ Table 2: Univariate Analysis Frequencies } \\
\hline Variables & $\mathbf{N}$ & Percent & & & & \\
\hline \multicolumn{7}{|l|}{ Gender } \\
\hline Male & 411 & 51.4 & & & & \\
\hline Female & 389 & 48.6 & & & & \\
\hline Total & 800 & $100 \%$ & & & & \\
\hline \multicolumn{7}{|l|}{ Social Networking } \\
\hline \multicolumn{7}{|l|}{ Sites Use } \\
\hline Less Often & 33 & $5.4 \%$ & & & & \\
\hline Every Few Weeks & 34 & $5.5 \%$ & & & & \\
\hline One To Two & & & & & & \\
\hline Times A Day & 73 & $11.8 \%$ & & & & \\
\hline 3-5 Days & 80 & $13.0 \%$ & & & & \\
\hline Once A Day & 148 & $24.1 \%$ & & & & \\
\hline Several Times & & & & & & \\
\hline A Day & 246 & $40.1 \%$ & & & & \\
\hline Total & 614 & $100 \%$ & & & & \\
\hline SNS Victimization i & & & & & & \\
\hline Last 12 Months & & & & & & \\
\hline Yes & 93 & $15.1 \%$ & & & & \\
\hline No & 522 & $84.9 \%$ & & & & \\
\hline Total & 614 & $100 \%$ & & & & \\
\hline Overall Cyberbully & & & & & & \\
\hline Victimization Tech & ques & & & & & \\
\hline None & 691 & $86.6 \%$ & & & & \\
\hline One & 41 & $5.2 \%$ & & & & \\
\hline Two & 45 & $5.6 \%$ & & & & \\
\hline All & 21 & $2.6 \%$ & & & & \\
\hline Total & 798 & $100 \%$ & & & & \\
\hline Facebook User & & & & & & \\
\hline Yes & 571 & $71.4 \%$ & & & & \\
\hline No & 229 & $28.6 \%$ & & & & \\
\hline Total & 800 & $100 \%$ & & & & \\
\hline MySpace User & & & & & & \\
\hline Yes & 150 & $18.7 \%$ & & & & \\
\hline No & 650 & $81.3 \%$ & & & & \\
\hline Total & 800 & $100 \%$ & & & & \\
\hline Twitter User & & & & & & \\
\hline Yes & 76 & $9.5 \%$ & & & & \\
\hline No & 724 & $90.5 \%$ & & & & \\
\hline Total & 800 & $100 \%$ & & & & \\
\hline
\end{tabular}


Table 3: Chi-Square for Traditional Bystander Engagement

\begin{tabular}{|c|c|c|c|c|}
\hline Variables & Never & Once in A While & Sometimes & Frequently \\
\hline \multicolumn{5}{|l|}{ Gender } \\
\hline Male & $6.8 \%$ & $16.3 \%$ & $35.7 \%$ & $41.1 \%$ \\
\hline Female & $10.7 \%$ & $18.0 \%$ & $42.6 \%$ & $28.7 \%$ \\
\hline $\begin{array}{l}\text { Chi-square } \\
\text { d.f. } \\
\text { N }\end{array}$ & $\begin{array}{l}9.961 * \\
3 \\
535\end{array}$ & & & \\
\hline \multicolumn{5}{|c|}{ SNS Victimization in Past 12 Months } \\
\hline Yes & $14.9 \%$ & $8.0 \%$ & $46.0 \%$ & $31.0 \%$ \\
\hline No & $7.6 \%$ & $19.0 \%$ & $37.8 \%$ & $35.6 \%$ \\
\hline
\end{tabular}

$\begin{array}{lc}\text { Chi-square } & 11.212^{*} \\ \text { d.f. } & 3 \\ \text { N } & 534\end{array}$

Facebook User

Yes

No

$8.2 \%$

$16.7 \%$

Chi-square

d.f.

$\mathbf{N}$

MySpace User

$$
\text { Yes }
$$

No

Chi-square

d.f.

N

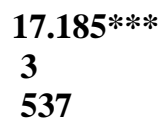

$18.4 \%$

$2.8 \%$

$37.3 \%$

$63.9 \%$

$36.1 \%$

$16.7 \%$

\section{Twitter User}

Yes

No

$4.1 \%$

$9.5 \%$

$8.2 \%$

$18.8 \%$

$50.7 \%$

$37.2 \%$

$37.0 \%$

$34.4 \%$ 
Table 4: Bivariate Correlations for Bystander Engagement

\begin{tabular}{llc} 
Independent Variables & $\begin{array}{l}\text { Pro-Social } \\
\text { Bystander }\end{array}$ & $\begin{array}{c}\text { Traditional } \\
\text { Bystander }\end{array}$ \\
\hline Age & .06 & .01 \\
Frequency of SNS Use & $.09^{*}$ & .07 \\
Parental Monitoring Techniques & $.17^{* * *}$ & -.07 \\
Perceptions of Cruel & $.10^{*}$ & .08 \\
On-line Environment & $.48^{* * *}$ & -.00 \\
Witness Pro-Social Behavior & $.17^{* * *}$ & $.10^{*}$ \\
Witness Joining & $.12^{* *}$ & $.25^{* * *}$ \\
Witness Ignoring & & -.03 \\
SNS Victimization in & $.18^{* * *}$ & $-.13^{* *}$ \\
Past 12 Months & $.15^{* * *}$ & \\
Overall Cyberbully & & \\
Victimization Techniques & & \\
\hline
\end{tabular}

$* P<.05, * * P<.01, * * * P<.001$

Table 5: T-Test for Group Differences by Sex

\begin{tabular}{|c|c|c|c|c|c|}
\hline Dependent Variables & Sex & $\mathbf{n}$ & Mean & Std. Dev & t-test \\
\hline Pro-Social Bystander & $\begin{array}{l}\text { Male } \\
\text { Female }\end{array}$ & $\begin{array}{l}255 \\
276\end{array}$ & $\begin{array}{l}3.06 \\
3.53\end{array}$ & $\begin{array}{l}1.922 \\
1.829\end{array}$ & $2.907 * *$ \\
\hline
\end{tabular}

$* P<.01, * * P<.05, * * * P<.001$

Table 6: T-Test for Group Differences by Frequency Social Networking Site Use

\begin{tabular}{lcllll} 
Dependent Variables & Facebook & n & Mean & Std. Dev & t-test \\
\hline \multirow{2}{*}{ Pro-Social Bystander } & Yes & 496 & 3.34 & 1.883 & 1.257 \\
& No & 35 & 2.92 & 1.935 & \\
& MySpace & & & & \\
& Yes & 124 & 3.33 & 1.957 & .165 \\
Pro-Social Bystander & No & 407 & 3.30 & 1.868 & \\
& Twitter & & & & \\
& & & & & \\
Pro-Social Bystander & Yes & 73 & 3.80 & 1.562 & \\
& No & 458 & 3.23 & & \\
\hline
\end{tabular}

$* \boldsymbol{P}<.01, * * \boldsymbol{P}<.05, * * * \boldsymbol{P}<.001$

Table 7: T-Test for Group Differences by SNS Victimization In Past 12 Months

\begin{tabular}{llllll} 
Dependent Variables & Victim & n & Mean & Std. Dev & t-test \\
\hline \multirow{2}{*}{ Pro-Social Bystander } & & & & & \\
& Yes & 88 & 4.06 & 1.485 & $4.963 * * *$ \\
& No & 443 & 3.16 & 1.924 &
\end{tabular}

$* P<.05, * * P<.01, * * * P<.001$ 
Table 8:

Model 1: Ordinary Least Squares Regression for Pro-Social Bystander Engagement

\begin{tabular}{|c|c|c|c|}
\hline Variables & B & SE B & $B$ \\
\hline Age & .09 & .05 & $.08^{\wedge}$ \\
\hline Gender & .32 & .16 & $.09^{\wedge}$ \\
\hline Frequency of SNS Use & -.04 & .06 & -.03 \\
\hline Facebook & -.48 & .40 & -.05 \\
\hline MySpace & .19 & .18 & .05 \\
\hline Twitter & .21 & .22 & .04 \\
\hline Parental Monitoring & & & \\
\hline $\begin{array}{l}\text { Techniques } \\
\text { Perceptions of Cruel }\end{array}$ & .19 & .06 & $.13 * *$ \\
\hline On-line Environment & .13 & .12 & .05 \\
\hline Witness Pro-social Behavior & .49 & .05 & $.45 * * *$ \\
\hline Witness Joining In & .10 & .08 & .06 \\
\hline Witness Ignoring & -.03 & .10 & -.01 \\
\hline SNS Victimization in & & & \\
\hline Past 12 Months & -.16 & .24 & -.03 \\
\hline Overall Cyberbully & & & \\
\hline Victimization Techniques & .29 & .12 & $.13^{*}$ \\
\hline $\mathbf{R}^{2}$ & .27 & & \\
\hline $\boldsymbol{F}$ & $12.58 * * *$ & & \\
\hline$N$ & 412 & & \\
\hline
\end{tabular}

Table 9:

Model 2: Ordinary Least Squares Regression for Traditional Bystander Engagement

\begin{tabular}{|c|c|c|c|}
\hline Variables & B & SE B & $B$ \\
\hline Age & -.01 & .03 & -.01 \\
\hline Gender & -.15 & .09 & -.08 \\
\hline Frequency of SNS Use & .03 & .04 & .04 \\
\hline Facebook User & .38 & .23 & $.08^{\wedge}$ \\
\hline MySpace User & .06 & .11 & .03 \\
\hline Twitter User & .28 & .13 & $.11 *$ \\
\hline Parental Monitoring & & & \\
\hline $\begin{array}{l}\text { Techniques } \\
\text { Perceptions of Cruel }\end{array}$ & -.06 & .04 & $-.09^{\wedge}$ \\
\hline $\begin{array}{l}\text { On-line Environment } \\
\text { Witness Pro-Social }\end{array}$ & .07 & .07 & .06 \\
\hline Behavior & -.02 & .03 & -.03 \\
\hline Witness Joining In & .04 & .04 & .05 \\
\hline $\begin{array}{l}\text { Witness Ignoring } \\
\text { SNS Victimization }\end{array}$ & .29 & .06 & $.25 * * *$ \\
\hline $\begin{array}{l}\text { In Past } 12 \text { Months } \\
\text { Overall Cyberbully }\end{array}$ & .08 & .14 & .03 \\
\hline Victimization Techniques & -.14 & .07 & $-.12 *$ \\
\hline $\mathbf{R}^{2}$ & .10 & & \\
\hline $\boldsymbol{F}$ & $4.59 * * *$ & & \\
\hline $\mathrm{C}_{\mathrm{C}}$ & 413 & & \\
\hline
\end{tabular}

